\title{
TWO ESSAYS ON THE ECONOMICS OF EDUCATION
}

\author{
A Dissertation Presented to \\ the Faculty of the Graduate School \\ at the University of Missouri
}

In Partial Fulfillment

of the Requirements for the Degree

Doctor of Philosophy

\begin{abstract}
by
XIANG LI

Dr. Michael Podgursky, Dissertation Supervisor
\end{abstract}

DECEMBER 2017 
The undersigned, appointed by the Dean of the Graduate School, have examined the dissertation entitled:

\section{TWO ESSAYS ON THE ECONOMICS OF EDUCATION}

presented by Xiang Li, a candidate for the degree of Doctor of Philosophy and hereby certify that, in their opinion, it is worthy of acceptance.

\begin{tabular}{c}
\hline Dr. Michael Podgursky \\
\hline Dr. Peter Mueser \\
\hline Dr. Shawn Ni \\
\hline
\end{tabular}

Dr. Rajeev Darolia 


\section{ACKNOWLEDGMENTS}

I would like to express my deep gratitude to my advisor Professor Podgursky for the continuous support of my Ph.D. study and related research, for his patience guidance, enthusiastic encouragement, and immense knowledge. His guidance helped me in all the time of research and writing of this dissertation. I could not have imagined having a better advisor and mentor for my Ph.D. study.

My grateful thanks are also extended to the rest of my thesis committee: Professor Mueser, Professor Ni, and Professor Darolia, for their insightful comments and encouragement, but also for the questions which invented me to widen my research from various perspectives.

I feel to acknowledge my indebtedness and deep sense of gratitude to Professor Wang whose valuable guidance and kind help given to me throughout my life in Columbia.

With a special mention to Weiwei Wu, Xueli Cao, Li Tan, Yifeng Jia, Hao Cheng and Xingpeng Wei. It was fantastic to have the opportunity to work with these talented colleagues. I am also grateful to the following university staff: Lynne Owen, Linda Dyer, Sheila Akers, Susan Leutschaft, and Valerie Kulp for their unfailing support and assistance.

Last, but certainly not least, a special thanks to my family. Words cannot express how grateful I am to my mother, and father for all of the sacrifices that they have made on my behalf. I would like express tremendous and deep appreciation to my love, Tengfei Wang who is the light of my life. I cannot completed this journey without his unconditional support and love. 
TABLE OF CONTENTS

ACKNOWLEDGMENTS ................ ii

LIST OF TABLES $\ldots \ldots \ldots \ldots \ldots \ldots \ldots \ldots$ v

LIST OF FIGURES $\ldots \ldots \ldots \ldots \ldots \ldots \ldots$ vii

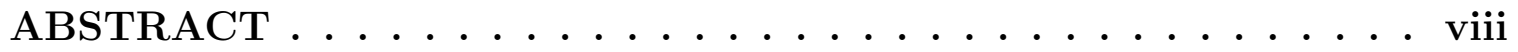

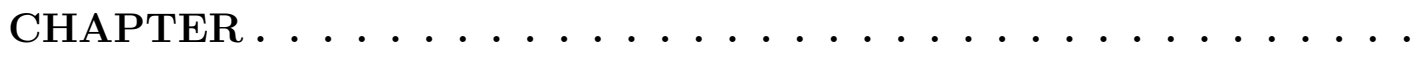

1 State Borders and Beginning Teacher Job Search . . . . . . . 1

1.1 Introduction . . . . . . . . . . . . . . . . . . 1

1.2 Data and Methodology . . . . . . . . . . . . . . 4

1.2.1 Data Description . . . . . . . . . . . . . . 4

$1.2 .2 \quad$ Model Setup . . . . . . . . . . . . . . . . . . . 6

1.3 Model and Result . . . . . . . . . . . . . . . . . . . . . . 8

1.3.1 Linear model . . . . . . . . . . . . . . . . . . . . 8

1.3.2 Mixed Logit Model . . . . . . . . . . . . . . . . . . . . . . 13

1.3.3 Robustness Check with Poisson Model . . . . . . . . . . . . 19

1.4 Conclusion . . . . . . . . . . . . . . . . . . . . . . . . . . 21

2 The Effect of the Implementation of the Electronic Benefit Transfer Program on Student Attainment . . . . . . . . . . 23

2.1 Introduction . . . . . . . . . . . . . . . 23

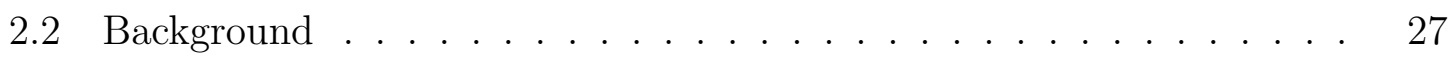

2.2.1 Implementation of EBT in Missouri . . . . . . . . . . . 27

2.2.2 Standard Test in the Missouri Public School System . . . . . . 28 
2.3 Empirical Strategy and Data . . . . . . . . . . . . . . 29

2.3.1 Data . . . . . . . . . . . . . . . 30

2.3.2 Difference-in-Difference Model . . . . . . . . . . . . . . . . . . 33

2.4 Difference-in-Difference Model Results . . . . . . . . . . . . . . 35

2.4.1 Results...................... 35

2.4 .2 Robustness Checks . . . . . . . . . . . . . . 37

2.5 Conclusion . . . . . . . . . . . . . . . . . . . . . 39

APPENDIX ...................... 41

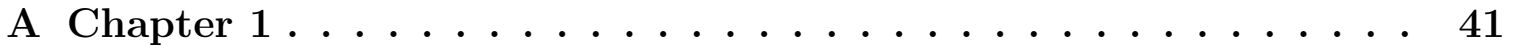

A.1 Pictures and Graphs . . . . . . . . . . . . . . . . . . . 41

A.2 Tables and Charts . . . . . . . . . . . . . . . . 42

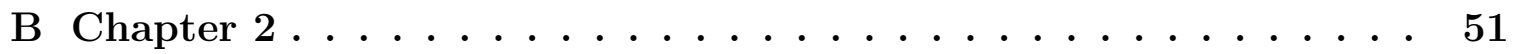

B.1 Pictures and Graphs . . . . . . . . . . . . . . . . 51

B.2 Tables and Charts . . . . . . . . . . . . . 56

BIBLIOGRAPHY ................... 70

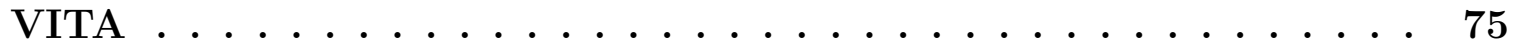




\section{LIST OF TABLES}

Table Page

A.1 Cross States Shares by Market Radius . . . . . . . . . . . . . . . 42

A.2 Comparison of The Cross State Shares with Prediction Value by Market Radius . . . . . . . . . . . . . . . . . . . . . . . . . . 42

A.3 Results of the Linear Regressions . . . . . . . . . . . . . . . . . . 43

A.4 Number of Alternatives by Market Radius . . . . . . . . . . . . . . . 44

A.5 Range of the Estimates for 50 Miles Radius Group . . . . . . . . . . . 44

A.6 Range of the Estimates for 100 Miles Radius Group . . . . . . . . . . 45

A.7 Range of the Estimates for 200 Miles Radius Group . . . . . . . . . . 46

A.8 The Median of the Estimates of 50 Miles Radius Group . . . . . . . . 47

A.9 The Median of the Estimates of 100 Miles Radius Group . . . . . . . 48

A.10 The Median of the Estimates of 200 Miles Radius Group . . . . . . . 49

A.11 Estimation by Poisson Approach . . . . . . . . . . . . 50

B.1 Number of Schools Took MAP/MMAT Math Test in Grade 8 . . . 56

B.2 Summary Statistics of Grade $4 \ldots \ldots$. . . . . . . . . . 56

B.3 Summary Statistics of Grade 8 . . . . . . . . . . . . 57

B.4 MAP standardized score of grade 4 in math . . . . . . . . . . . 57

B.5 MAP standardized score of grade 8 in math . . . . . . . . . . . 58 
B.6 MMAT and MAP standardized score of grade 4 in math . . . . . . . 59

B.7 MMAT and MAP standardized score of grade 8 in math . . . . . . 60

B.8 MMAT and MAP standardized score of grade 4 in math conditional . 61

B.9 MMAT and MAP standardized score of grade 8 in math conditional . 61

B.10 Difference-in-Difference of the Standardized MAP Math Test Score of Unconditional Group in Grade 4 . . . . . . . . . . . . . . . . . . 62

B.11 Difference-in-Difference of the MAP Math Test Standardized Score of Unconditional Group in Grade 8 . . . . . . . . . . . . . . . . . . 62

B.12 Difference-in-Difference Estimates of the Unconditional Sample with School Fixed Effect . . . . . . . . . . . . . . . 63

B.13 Difference-in-Difference of the Standardized MAP Math Test Score of Conditional Grade 4 . . . . . . . . . . . . . . . . . . 64

B.14 Difference-in-Difference of the Standardized MAP Math Test Score of Conditional Grade 8 . . . . . . . . . . . . . . . . . . . . 64

B.15 Difference-in-Difference Estimates of the Conditional Sample with School Fixed Effect . . . . . . . . . . . . . . . . .

B.16 Difference-in-Difference Estimates of the Unconditional Sample with School Fixed Effect and Cluster at County Level . . . . . . . . . . . . 66

B.17 Difference-in-Difference Estimates of the Conditional Sample with School Fixed Effect and Cluster at County Level . . . . . . . . . . . . . . . 67

B.18 Difference-in-Difference Estimates of Unconditional Sample in 1997 and 1998 with School Fixed Effect . . . . . . . . . . . . . . 68

B.19 Difference-in-Difference Estimates of Conditional Sample in 1997 and 1998 with School Fixed Effect . . . . . . . . . . . . . . . 


\section{LIST OF FIGURES}

Figure

Page

A.1 Local labor market for teachers . . . . . . . . . . . . . . . . 41

B.1 EBT Program Implementation Schedule Map for Missouri Counties . 52

B.2 Mean of the Standardized MAP Math Test Score in Grade $4 \ldots \ldots$

B.3 Mean of the Standardized MAP Math Test Score in Grade 8 . . . . 53

B.4 Mean of the Standardized MMAT/MAP Math Test Score in Grade 454

B.5 Mean of the Standardized MMAT/MAP Math Test Score in Grade 855 


\begin{abstract}
In this study I focus on two related topics on the economics of education: one is the teacher labor market and the other is factors affecting student academic achievement.

Chapter 1 empirically test the effect of state boundaries on beginning teacher job search behavior. The Beginning Teacher Longitudinal Survey(BTLS), a national survey data of beginning teachers, was employed. I run a linear regression to investigate the effect of state boundaries on distance between the beginning teachers job and the Teacher Preparation Program(TPP) and find that beginning teachers tend to find jobs 'inland' when their TPP is near a state border. A mixed logit model with the McFadden Randomization Approach was applied to illustrate the border effect on the probability of employment in a given school. I find that a beginning teacher is 80 percent less likely to teach in a school on the other side of a state border from her TPP. I conclude that frictions associated with state borders, non-reciprocal teacher licensing being a likely candidate, distort early career job search for teacher candidates.

Chapter 2 examines the effect of the Supplemental Nutrition Assistance Program(SNAP) payment method change on student achievement. Switching from cash to non-cash transactions influences street crime, then student attainment. A differencein-difference method was used to capture the impact of the implementation of the Electronic Benefit Transfer (EBT) program, a county-level intervention, on students academic performance in Missouri during 1997 to 1998. I find the standardized math test score of the students in the counties that had implemented EBT program is 0.07 standard deviations higher in grade 8 than students in the counties that still using paper checks. This results provide evidence that switching to non-cash transactions can enhance student educational outcomes.
\end{abstract}




\section{Chapter 1}

\section{State Borders and Beginning Teacher Job Search}

\section{$1.1 \quad$ Introduction}

The public school teacher shortage has been discussed for decades. There are several factors which make this problem even worse, like teacher tenure, teacher pension systems, and teacher licensure policy. All these increase the teacher mobility costs, introduce more frictions in the teacher labor market, and make the labor market less efficient. Broadly speaking, there are two kinds of migration of the teacher labor force: within-state migration and cross-state migration. Because of the lack

of nationwide data, most of the previous research focused on the migration within a state(Allensworth et al. (2009); Elfers et al. (2006); Hanushek et al. (2004)). However, cross-state migration happens and it does affect teacher labor supply. Teacher pension and teacher licensure policy are two factors that increase the frictions of the labor force and reduce cross-state teacher migration. Most of the teachers in public school systems are enrolled in a state pension plans which impose a penalty when teachers 
transfer to another state. This large financial cost makes the cross-state mobility much harder for teachers, especially for experienced teachers. Recent literature has examined the frictions created by the teacher pension system (e.g. Koedel et al. (2011); Costrell and Podgursky (2010)). In this paper we will focus on another factor creating cross-state teacher migration frictions: teacher licensure policy.

State level teacher licensing and certification helps the state ensure all teachers meet the standard of the state. But the licensure policy also creates a barrier along state borders and reduces cross-state teacher migration. As different states have different requirements and standards for their public school teachers, so the teacher preparation programs (TPP) are different by state. The curriculum setting and test requirements may vary between different TPPs to meet state preferences and licensing requirements. The different TPPs makes the recognition of teacher licenses from different states much harder. The state level licensure policy builds up a barrier along the state border. What we observe is that the state border reduces cross-state teacher mobility. For simplicity, in this paper we use 'border effect' as a metaphor for the effect associated with different state level licensure policy and state TPPs. As a result of the border effect, teachers who plan to teach in another state have to face complicated procedures and may need to take extra classes or tests. The National Association of the State Directors of Teacher Education and Certification (NASDTEC), a teacher license reciprocity agreement widely recognized by 41 states and D.C., may make the cross-state mobility a little bit easier for the teachers among these states, but even under this reciprocity agreement teachers have to spend time and effort to get certificated in each state. Evidence has been reported that teachers who want to move cross-state were discouraged by the complicated licensure policy (Coggshall and Sexton (2008); Goldhaber et al. (2015a,b)). What's worse, the complicated licensure policy not only affects teacher job search behavior, but may also 
affect student achievement. Kim et al. (2016) find empirical evidence that proximity to a state boundary has a negative effect on student achievement.

Goldhaber et al. (2015a,b) use the administrative data form Washington and Oregon to provide an example of how the state boundaries affect teacher mobility. Goldhaber's research is limited to two states. What we want to check is the border effect on the national level. However, there are two challenges we have to face when we want to deal this. One is the lack of the national level data. Teachers can move all around the country and this makes it hard to track teachers based on available state administrative data. The other challenge we face is the mixed effect from both teacher pensions and teacher license. Its hard to distinguish their separate effects on the teacher labor market.

In this paper we try to identify the border effect by focusing on the beginning teacher job search. As beginning teachers, they are not in a teacher pension plan, nor are they tenured, two factors that reduce teacher mobility. To do so we exploit data from the Beginning Teacher Longitudinal Survey (BTLS). BTLS is a national survey that tracks teachers from their teacher preparation program into their early years in the workforce. With these data we will investigate the effect of state boundaries on the distance between the beginning teacher's job and their training program and the impact of state boundaries on this variable.

In the following, we begin by describing the data and empirical methods we apply, then present our results and a concluding discussion. 


\subsection{Data and Methodology}

\subsubsection{Data Description}

To analyze the effect of state borders on the teacher labor market, we use the BTLS data set. BTLS is a five-wave longitudinal survey based on the 2007-08 School and Staff Survey (SASS). The SASS 2007-08 uses the universe of public schools in the 50 states and D.C. SASS employs a stratified probability proportionate to size (PPS) public school sample. The sample was allocated to each state by grade range and school type. SASS uses the number of full-time-equivalent teachers in each school as the measure of size. In a selected school the Census Bureau classifies teachers into five categories by experience and the willingness to stay based on the information provided by the principals. Then teachers are selected with equal probability within each category. Based on the selected teachers in SASS 2007-08, BTLS includes all the teachers who report their first year of teaching as being 2007 or 2008 in a traditional public school or a public charter school. Details of the sampling frame and sample selection can be found in Gray et al. (2015). As beginning teachers, they have no prior tie to a particular teacher pension plan, nor are they tenured. There is no sunk cost of these two factors for the beginning teachers to take into account when they are searching for a job. The biggest roadblock for them to teach across the state line is the licensure issue we noted above. Keeping this in mind, we will use the data from the first survey year of BTLS to investigate the effect of the state border on the teacher labor market, especially on teacher mobility.

We use the first survey year data, the 2007-2008 academic year, from BTLS as our sample. There are 1,990 beginning teachers who just graduated in the BTLS. First we link this data set with the Common Core Data $\left(\mathrm{CCD}^{1}\right)$ set 2005-06 to introduce

\footnotetext{
${ }^{1}$ Common Core of Data (CCD) is a program of the U.S. Department of Education's National
} 
geospatial information on the public school. By matching the unique CCD school ID we can link 1,970 out of 1,990 teachers in the BTLS. Then we use the teacher's education level as the basis to select the sample. There are 1,920 out of 1,970 eligible teachers who have at least a bachelor's degree. What we are interested in is the geospatial location of the teacher's TPP, so we use the IPEDS ID in BTLS to link the BTLS data set to the Integrated Postsecondary Education Data System (IPEDS ${ }^{2}$. There are 1,850 teachers who can be linked to the TPPs in IPEDS with an eligible IPEDS ID. Meanwhile, we checked the physical address of colleges with TPPs to make sure the geo-information is accurate. 42 of the 1,850 teachers have incomplete information on the public school, so we have dropped these observations. We use the remaining 1,808 teachers as the universe of our sample.

By linking the BTLS to the CCD and IPEDS we can observe the geospatial information on the teacher preparation program and the public schools where they found their first teaching job. There are two aspects we are interested in from the geospatial information. One is the distance between the TPP and teacher's public school where they get employed, and the other one is if the public school is in the same state as the TPP. The Table A.1 represents basic statistics of the information about the novice teacher location choice.

In Table A.1 the column labeled 'Distance' is the distance in miles between public school's location and the TPP where the teacher was trained. ' $\mathrm{N}$ ' is the number of teachers whose distance is in this category. We determine each category by checking if the public school's state is same as the TPP's state. If they are not in the same state, this teacher is counted as 'Cross-State', otherwise she is counted as 'within-state'. We

Center for Education Statistics that annually collects fiscal and non-fiscal data about all public schools, public school districts and state education agencies in the United States.

${ }^{2}$ The Integrated Postsecondary Education Data System (IPEDS) is the Department of Educations National Center for Education Statistics (NCES) core postsecondary education data collection program. 
use the number of cross-state teachers divided by the total teachers in that category to get a percentage value as 'Cross-State-Pct'.

We find there are 864 teachers who get a job within 50 miles of their TPP. That is 46.7 percent of our sample. If we expand the radius to 200 miles this proportion increases to 76.6 percent. These numbers suggest that beginning teachers usually find their jobs in a local labor market that is close to the TPP where they got trained.

\subsubsection{Model Setup}

In Table A.1 more than 76 percent of the beginning teachers in the BTLS find a job within 200 miles around their TPPs. However, only 9.6 percent of them find a job in a state different from where they were trained. We think there may exist a 'own state' preference by teachers for public schools. The own state preference implies that teachers prefer to stay within the TPP's state, or the public schools prefer to hire employees who get their training from its own state. No matter what is the representation of this 'own state' preference, we do observe teachers are more likely to get a job in the same state with their TPP. And the own state preference we observe in the beginning teachers labor market may be induced by a border effect. Because of the existence of the border effect, it's hard for the beginning teacher who gets licensed and trained in one state to teach in another state. Consequently, teachers would like to look for teaching in their training state first. Also, the principals in the public schools may prefer to hire someone who is familiar with their state and its requirements.

In this paper we focus on the frictions in the teacher's local labor market. We define the local labor market to include traditional public schools and public charter schools around the training program within a fixed radius. We know that the larger 
the radius we define the more vacancies there will be in the local market. At the same time, the number of cross-state vacancies will generally increase as well. If there is no own state preference for both teachers and public schools in the local labor market, the 'Cross-State-Pct' we calculate should be close to the proportion of the cross-state vacancies in the local labor market. Based on the data we try to figure out if the 'own state' preference does exist in the teacher labor market. Table A.A.2 helps us illustrate this phenomenon.

In Table A.2 we use the TPP as the center and pick a radius to define the local labor market. The prediction column is calculated using the total teacher count from cross-state schools within the local labor market we defined divided by the total teacher count in the local labor market. Column ' $\mathrm{N}$ ' and 'Cross-State-Pct' are the same as in Table A.1. The column 'Diff' is the difference using 'Cross-State-Pct' minus 'Predict'. The column 't-value' is used to test the significance level of the difference. If the 'own state' preference is weak, or there is no 'own state' preference in the teacher labor market, the prediction and the real proportion should be close. However, Table A.2 shows the observed proportion is much smaller than the prediction results. And most of the differences between these two proportion are highly significant. This suggests that the own state preference may exist.

We observe the own state preference in the teacher labor market for beginning teachers in our data set. In the following step, we try to create a scenario to check when the total number of vacancies is fixed in the local labor market, if there are more cross-state jobs, what will the novice teacher's response be? Would they pay more to re-certify in another state or expand their search radius to get a job within the state. If we can find evidence that shows the novice teachers expand their search to greater distance to compensate for the lack of within state jobs in the local labor market, we may say the the 'own stat' preference introduced by the state border effect does 
reduce teachers mobility across states.

Figure A.1 can help us illustrate the logic of our methodology. For each teacher in BTLS we define a local labor market with a chosen radius. We use 10, 15, 30, or 50 miles. We calculate the total number of teachers from all the public schools as an estimate of the total local market demand. Meanwhile, we count the total number of teachers from qualified public schools that are not located in the TPP's state but are still in the local labor market. We use this number as an estimate of local market cross-state demand. We will use this information in our regression analysis.

We find that there is an own state preference in the teachers' labor market, and the state border effect trends to keep teachers within the state where they were trained. In the following part we will use our model to illustrate the state border effect and explore how much it will affect teacher choice.

\subsection{Model and Result}

\subsubsection{Linear model}

As a first step we want to use a linear model to reveal the the findings we get in the previous section. The phenomena we want to test here is the existence of the state border effect on the teacher labor market. We use the relationship between the cross-state vacancies in the local labor market and the distance of the public school from TPP to check this effect.

Based on these findings we use a linear model of distance and local labor market 
conditions to capture this relationship:

$\ln ($ distance $)=\beta_{1} \cdot$ CrossStateDemand $+\beta_{2} \cdot$ TotalDemand $+\gamma \cdot$ Control $+\alpha_{1} \cdot$ State $+\alpha_{2} \cdot$ Location

The dependent variable $\ln ($ distance $)$ measures the distance between the TPP and teacher's job location. We are interested in two covariates: 'Cross-State Demand' is the estimate of the cross-state vacancies in the local labor market with different radii from the TPP. We create this variable by summing up the number of teachers in a cross-state public school in the local labor market. We use the same method to estimate the 'Total Demand' which represents the total number of teachers in the local labor market.

For a local labor market, we believe the more jobs in the market the closer the teacher will choose to work, as it is easier for teachers to find a job close to the TPP in this case. So we expect a negative coefficient of $\beta_{2}$. For $\beta_{1}$ we expect a positive value. The hypotheses is when the total number of vacancies is fixed, the more jobs are across a state line, the further the teacher will have to move. New teachers need to balance the cost of getting a license from another state and finding a more distant job in their state. If the state border effect does affect teacher labor market and the own state preference does exist, teachers have to expand their search radius.

The variable 'Control' is a vector of other variables that might affect job search. That includes: age, race, gender, education level, wage, chosen school's poverty level. We use qualified national school lunch program (NSLP) student percentage to measure the school poverty level. We also include the chosen school's minority student percentage. By controlling for these covariates we try to reduce potential omitted variable problems. We also include state fixed effects and location fixed effects in the model. We divide all the teachers into five different location groups: large city and 
suburb, midsize city and suburb, small city and suburb, town, and rural area.

We present our results in the following sections by different groups of teachers.

\section{Results}

We run model (1) with four different local labor market radii: 10, 15, 30 and 50 miles from the TPP. We report our key coefficients of interest: Cross-State Demand and Total Demand on Table A.3.

Full Sample In Table A.3.A we report the estimated coefficient, the standard error, P-value and the mean value of the variable in this group. Here we divide the number of Cross-State Demand and Total Demand by a thousand. For example the mean of Cross-State Demand of 10 miles radius is 0.15639 which means 156.39 vacancies.

We begin with the coefficient $\beta_{2}$ for 'Total Demand'. This can be treated as the thickness of the local labor market. The relationship between this variable and $\ln ($ distance $)$ is negative. The interpretation is straightforward. The more vacancies in the local labor market, the easier for the teacher to find a local job, which means the shorter is the distance to their job. For example, for a 10 mile local labor market, when there are 1,000 more vacancies, the teacher would to be 9 percent closer to the job. We find the coefficients for 10 miles and 15 miles radius are significant, and the effect diminishes with the radius of the local labor market.

For $\beta_{1}$ we find from Table A.3.A that Cross-State Demand and $\ln ($ distance $)$ have a positive relationship which is consistent with our hypotheses. When we control the total number of vacancies in the local market, the more cross-state vacancies there the more distant the teachers will search for a job. And we can find for 15 miles and 
50 miles, the coefficients are significant. Using the estimate of 15 miles as an example, the magnitude of the coefficient is 0.08231 . It means in the local labor market which uses 15 miles as radius, when there are 1000 more cross-state vacancies, the teacher would travel 8 percent further to get a job. We also find when the radius goes up the magnitude of the coefficient decreases.

Table A.3.A is for all the teachers of our data set. We will apply the same model to different sub-groups to check the relationships we are interested in.

Teachers who graduate from a public college VS. a private college In BTLS we cannot observe the address of the high school address of a teacher attended. It's hard for us to distinguish the effect of the hometown on the teacher's job location choice. Boyd et al. (2005) show that the effect of hometown and college are fairly similar. We use the group who graduate from a public college to investigate this hypothesis, because we believe that most of teachers who enroll in a TTP in a public college might be the resident of that state. By adding 'public college' fixed effect we can reduce the hometown effect to improve the accuracy of our estimate. Table A.3.B presents the result by adding the 'public college' fixed effect. By comparing Table A.3.A and Table A.3.B we see the significant level of the coefficient estimation improves. The direction of the relationship is the same and the magnitude of the estimates tends to increase.

The home effect can be explained by the 'own state' preference as well. Actually, no matter whether the effect is interpreted as home effect or college effect, the reason behind the effect is likely to be state level teacher certification. When our teachers applied to colleges, they might have little understanding about the complexity of teacher licenses, and they might not know where they will go after graduation. They would like to choose a public college in their home state for financial and family 
reasons. After they graduate, they realize that the state level teacher certification prevents them from teaching in another state. They have to and would like to find a job within the state. And this is what we observ as home effect.

We separate the teachers who graduate from a private school as a sub-group and present the regression results in Table A.3.C. We find neither the 'Cross-State' or the 'Total Demand' is statistically significant. One possbile explaination for this is the sample size for this group is much smaller, especially when we take the state fixed effect and location fixed effect into account. Another explanation we may have is that the teachers who graduate from a private school probably have more resources from their family or college and these kind of resources can help them relax the geo-location constraints when they are trying to find a job. However, based on the available data we cannot test this hypothesis.

Teachers who graduate from a less selective college We also want to know for the group of teachers who graduate from a less selective college whether they have a stronger border effect or not. We use Barron's selective index as our standard. We drop the teachers who graduate from the most selective and highly selective college, and there are 1,628 teachers left.

There is no big difference between Table A.3.D and Table A.3.A except the coefficient of 'Cross-State Demand' for the local labor market with a 50 miles radius. The reason behind this is the group of teachers who graduated from less selective college takes $90 \%$ in the full group. That is why the regression results of these groups are similar. 
STEM teachers Now the last sub group we want to test are STEM teachers. We select the teachers who report they teach science, math, physics, chemistry, biology or similar fields. There are 366 STEM teachers in BTLS which is 20.24 percent of all the 1,808 teachers.

From Table 3.E we find there is no significant coefficient estimates no matter for 'Cross-State Demand' or 'Total-Demand'. This result makes sense as the STEM teachers are highly demanded by many schools and school districts (Hutchison (2012)). As a result of shortages states may relax the certification restriction for the STEM teachers to make the cross-state migration easier for them. Because they are in high demand, even in a local labor market that has fewer vacancies STEM teachers still can find a job without a more distant move.

Based on the results present above we find for some local labor markets the more cross-state jobs there are the further the teacher travels to get a job. Actually, this positive relationship is evidence of the existence of 'own state' preference. As the teachers in the BTLS are all beginning teachers, the most important reason for the 'own state' preference is the state border effect associated with the teacher licensure policy. This linear model reveals the state border effect. And we find state borders reduce teacher cross-state migration.

\subsubsection{Mixed Logit Model}

In the previous section 1.3.1 we employed a linear regression model to investigate the relationship between distance of the teacher's choice from TPP and the local labor market conditions. We find when the total demand in the local labor market is fixed, the more cross-state demand in the market the greater is the distance to the teacher's job. This linear regression helps us identify own state preference on the cross-state 
vacancies. However, we are still not clear about the magnitude of this border effect. In another words, we are still not clear how likely a teacher would be to get an in-state job instead of a cross-state job when all the other factors are the same. In this section we will investigate the teacher's probability of choosing a cross-state vacancy by using mixed logit model(Boyd and Mellman (1980) and Cardell and Dunbar (1980)).

Unlike the conditional logit model which was introduced by McFadden et al. (1973), the mixed logit model relaxes substitution patterns and make random taste variation possible (Train (2003)). We construct the benchmark of our mixed logit model. This model allows us to examine a novice teacher who faces several job vacancies how likely the teacher will get an in-state job instead of a cross-state job.

The mechanism is similar to the linear model. Using the TPP's location as the center with a chosen radius we draw a circle. We assume this circle is the search area of the teacher. All the public schools with the grades the teacher is qualified to teach can be the teacher's choices.

However, there are challenges to setting up the model. First of all, by drawing the circle, we need to recognize that teachers have different choice sets. The number of choices in their sets are different and the alternatives in the set are different. This ask us to check the Independence of Irrelevant Alternatives (IIA) assumption which implies that the probability ratio of individuals choosing between two alternatives does not depend on the availability or attributes of the other alternatives in a logit model. Fortunately, mixed logit model fully relaxes the IIA condition. (Cushing and Cushing (2007); Train (2003)) We do not need to worry about the IIA condition.

Another challenge we face is the large choice set teachers have. Table 4 presents the mean and median of the number of the alternatives in the teachers choice set for different radii we choose. We find when the radius is 200 miles, there are more than 4,000 alternatives on average for a teacher. The large choice set is cumbersome to 
estimate the coefficients with the mixed logit model. We thus followed the suggestion in McFadden (1978). By using smaller choice sets which are randomly selected from the full choice sets we will have consistent estimates. By adopting this approach, we choose different sizes of subsets from the full choice set for the mixed logit model. By comparing the estimate results from different subsets we can check the consistency.

The mixed logit model we set up is:

$$
\pi_{j k}=\frac{\exp \left(\beta \cdot X_{j k}+\gamma_{j}\right)}{\sum_{l \in R_{j}} \exp \left(\beta \cdot X_{j l}+\gamma_{j}\right)}
$$

In model 1.2 subscripts $j$ represents teacher, $k$ is the public school where the teacher works. $l$ is all the other alternatives in the teacher's choice set $R_{j} . X_{j k}$ is the characteristics of alternatives which includes: $\log$ value of the distance between college and the alternative; a dummy variable to compare the state of the alternative to the state with the state of the TPP, we named this dummy 'cross'; the size of the school which we use the total teacher number to present, the school's poverty level (NSLP), minority percentage, the number of students per teacher, and the location of the school. $\gamma_{j}$ is the component representing the unobserved variables for different alternatives of different teachers. It is similar as a random effect in a linear model. $\gamma_{j}$ represents the variations in tastes that are related to the unobserved attributes.

For the choice set $R$, we choose 50 miles, 100 miles, and 200 miles as three different search radii for all the teachers to set set up three different groups. For each group we draw three subsets with different number of alternatives from the full set. These three different sizes of the selected choice set are: 10, 15, and 20. To set up these choice set we have two steps. First, we randomly draw 9, 14, or 19 public schools as the alternatives of the teacher's choice set. Then combining with the teacher's chosen public school we formalize a choice set with alternatives for each teacher. So, for each 
teacher there will be three groups of alternatives which choose by different radii. And in each group there will be three different subsets with different sizes: 10, 15 or 20 .

The reason we choose three different radii groups is that we wish to focus on the local labor market instead of a national wide job market. We define three different levels of local labor markets. The observations we choose are the teacher who chose his or her job within 200 miles. This may introduce selection bias for the viable $\ln$ (distance). That's why we choose three different radii and adopt the multivariate adaptive regression splines on $\ln$ (distance). The knots we used in the hinge function here is 25 and its multiples. For example, we use 25 as knot for the 50 miles group. And 25, 50, 75 as knots for the 100 miles group. We want to check the consistency of the estimation. If the estimates of hinge function are similar for the different radii groups, we may conclude that sample selection bias is not a problem as not matter what radius we choose the effects from different knots of $\ln$ (distance) are similar.

The reason we choose three different sizes of subset is to test the consistency of the estimation by varying number of alternatives. Within the same radius group if there is no significant difference among the estimations of the three different sizes of subset, then we can say the size of the subset doesn't effect the consistency of the estimation.

For each radius group we randomly select 101 times for one subset. So we do the mixed logit estimation 101 times for each subset which means 303 for each radius group. Then, for each subset we rank all the estimates by the estimated value. We report the maximum ,minimum and median of the estimates with other statistics, including: standard error, t-value and the the odds ratio. The standard error we use here is calculated from two parts. One part is from the mixed logit regression, and the other part is the standard error of the 101 standard errors. In this way we can make sure we are not overestimating the significance of the estimate. 
Table A.5 to Table A.7 shows the range of the estimates of each variables for three different subsets of three different radii groups. The variable we are most interested in is the dummy variable 'cross'. If the alternative is within-state cross equal to 1 , otherwise cross equal to 0 . For Table A.5 to A.7 we find that the subset groups does not matter, or the maximum value or the minimal value, all the estimates of the variable cross are highly significant. Furthermore, for different subsets the range of the cross's estimates are close. When we take a look at the median value of this estimate from Table A.8 to Table A.10 we find within the same radius group the estimates are very similar for all the three different subset groups. When we compare the estimates from the three different radii group, we can see the absolute value of this coefficient increases slightly with an increase of the radius, but the differences between these estimates are not statistically significant. This result is consistent with the result from the simple linear model from 1.3.1. We can conclude that the state location of a school will have very strong negative effect on the beginning teacher job search. When all the other factors are the same, compared with a within-state public school, a novice teacher will about $80 \%$ less likely be employed in a cross-state public school for her first job.

Another variable we are interested in is the log value of the distance between college and public schools. As we mentioned above because we use three different radii to select the sample, we use a spline on the log value of the distance. For the 50 miles radius group we use 25 miles as the knot. So there are two variables, $\ln ($ dist1) and $\ln ($ dist2) in this group. For the 100 miles radius group we have three knots, 25, 50 and 75. And by these three knots we have four different variables for the log distance. We need to pay attention that the first two are the same with the 50 miles group. For the 200 miles, we use the same knots as 100 miles. And we add two more knots: 100 and 150 miles. As a result, there are six variables for log distance in 
this group. And the first four variables are identical with 100 miles group. Through Table A.5 to Table A.10 we have several findings for this variable. First of all, we find the magnitude of the effect increases with the distance. The more distance the public school is located, the less probability the novice teacher would like to work in this school. From Table A.10 we can see when the distance is within 25 miles, the probability of the novice teacher choose this school is $25 \%$ less than she or he choose the school which is exact at the place of the TPP. When the the distance increases to the range between 150 miles and 200 miles, this number increase to $53 \%$ less. The magnitude doubles. Next, we find that the estimates, no matter what the estimation range or the median value, by three different subsets within the same radius group are similar. In addition, the estimates by three different radii groups are very close. This can be the evidence that we didn't introduce selection bias as the sample is selected. Last but not the least, all the estimated coefficients are very significant. All the median of the estimates are highly significant.

Among the rest of the variables, 'Size' which is the total number of teachers in the public school, is highly significant. As we expect, 'Size' has a positive effect on teacher's choice. A beginning teacher is more likely to find a job in a public school which has large numbers of teachers. 'NSLP', the National School Lunch Program, which we use to represents the poverty level of the public school, does not have a significant effect on teacher's choice. Neither does 'Pupil Teacher Ratio'. The estimate of the variable 'minority' is complicated. The median of the estimation is weakly significant, but when we take a look at the range of this estimation through Table A.5 to Table A.7 not all the 101 estimate are significant. Actually only a little bit more than $50 \%$ of estimates are significant in this estimation. Based on this it is really hard to determine whether the beginning teacher is more likely to get a job in a high minority proportion school or not. 
By applying the McFadden randomization approach, we randomly select three different subsets in each radius group and get similar results for the location characters: distance and state. The regression results illustrate beginning teachers are more likely to get a job in a public school which is the same state with their PPT. And we find a new teacher is 80 percent less likely to teach in a school on the other side of the border. These findings are consistent with the conclusion from the simple linear regression, the 'own state' preference exists and the state border effect induces the state borders to reduce teachers cross-state migration.

\subsubsection{Robustness Check with Poisson Model}

In the section 1.3 .2 we used a mixed logit model by applying the McFadden Randomization Approach to estimate the effect of the the public school location, distance and state, on beginning teacher job search. In this section we will adapt another method to investigate the same issue, and check if the result is consistent with the results we get in section 1.3.2.

Guimaraes et al. (2003, 2004) proves an equivalence relationship between the likelihood functions of the conditional logit model and Poisson regression. We take advantage of this equivalence, and apply the Poisson regression to estimate the coefficient for the conditional logit model. The alternatives in the choice set of the conditional logit model are converted into observations in the Poisson regression. By maximizing the likelihood function of the Poisson regression we get the estimated coefficients. The interpretation of these estimates from the Poisson regression is same as the interpretation of the conditional logit model.

In contrast to the McFadden randomization approach, the Poisson approach can take all the alternatives into the model. The limitation of the large choice set problem 
is overcome by this method. By taking advantage of this method we apply the Poisson regression to our three different radii groups and the results is presented by Table A.11.

First, we focus on the estimates of the location characters, distance and state, from this Poisson approach. By comparing Table A.11 with Tables A.8 to A.10 we find the magnitude of some estimates in Poisson approach are larger than the magnitude of median value of McFadden Randomization Approach, especially for the first 2 estimation in the log distance group. When we compare Table A.11 with Tables A.5 to A.7 we find all the estimation of 'cross' are in the range of the estimation from McFadden randomization approach. All the estimates of the location characteristics in 200 miles group are in the range of Table A.7. Estimates of the log distance value in the 50 and 100 miles group have somewhat overestimate the effect.

For the other variables, 'size' has the same direction and similar significance as we did in the McFadden Randomization Approach, but the magnitude is smaller. For 'NSLP' and 'Minority', the sign of these two estimates are opposite with the sign we get in section 1.3.2. And the results here not very significant either. This confirms that estimates for these two variables in section 1.3.2 are not reliable.

By comparing the results with Poisson approach and McFadden Randomization Approach, we find the estimates of the location variable 'cross' are consistent. We can conclude most new teachers will find a job and teach in the state where their TPP locates. Whether this is because teachers prefer to work within the state where they get their training, or the public schools prefer to hire teachers graduate from the same state, the result is clear. When all the other conditions are the same, a cross-state public school may make the probability of a teacher teach in this school dropped by more than $80 \%$. 


\subsection{Conclusion}

In this paper we investigate the effect of teacher state level license on a beginning teacher's cross-state mobility. By employing the BTLS data we have a group of new teachers. For this group of teachers, the roadblock of teaching in another state is the different state level license requirements and the different TPPs. Because the existence of this issue, it's easier for teachers to find a job and teach in the state where they were trained. We call this phenomenon as 'own state' preference. The 'own state' preference is a representation of the state border effect. A more direct expression of the border effect from the data is the state boundaries reduce teachers cross-state migration and make the teacher labor market more local.

By checking the relationship between the distance of teachers working school from TPP, with the local labor market condition, we identify the border effect. With a straightforward linear model we check and estimate the border effect. The positive estimated coefficient shows that when other conditions are the fixed, the more crossstate vacancies, the further teachers travel to get a job. This result show us the existence of the 'own state' preference and the state border effect.

We apply the mixed logit model with the McFadden randomization approach to our data to estimate the magnitude of the state border effect. We find when all the other conditions are the same, the probability that a teacher chooses a crossstate school drops by more than 80 percent. Adapting the Poisson approach as an robustness check we see the the estimation of the cross-state dummy is consistent between these two approaches. We find significant border effects on new teacher employment. The most reasonable interpretation of this finding is differences in state level teacher licensure policy, but we can not rule out factors which may lead a TPP to favor placements in its own state. This might include TPP 'own state' preference 
for teaching placement. This effect is large. More than 80 percent probability for this school be chosen by the teacher will drop if this school is not in the state where the teacher have license.

State governments use teacher license to ensure all the teachers are qualified. This is a way to guarantee the quality of the teacher's cohort. However our paper shows the variation of the license requirement between different states may reduce the cross-state teacher mobility and make the teacher labor market more localized. This reduces the efficiency of the teacher labor market. In addition, it exacerbates the shortage of public school teachers. A unified teacher license requirement for different states would likely increase labor mobility substantially. 


\section{Chapter 2}

\section{The Effect of the Implementation of the Electronic Benefit Transfer Program on Student Attainment}

\section{$2.1 \quad$ Introduction}

Student achievement is an essential part of the education system in evaluating student performance and teacher quality. It can be affected by many factors. Some of these factors can be controlled within the schools, such as: class size, teacher quality, cultural environments of the school. Some of the factors are out of the school's control, such as: socioeconomic status, students background and family support. In this project we investigate the effect from one exogenous factor, a shift of the Supplemental Nutrition Assistance Program(SNAP) payment method, on the students achievement. Missouri state starts switching to Electronic Benefit Transfer (EBT) to issue SNAP benefits in 1997 and 1998. We use this implementation as a case of government benefits payment method change in this study. 
To test the effect of the implementation of the EBT program we need to figure out how does it work. One of the possible explanation related to the steet crime. The implementation of the EBT program influences the student achievement in two steps. The first step is the implementation of the EBT program affects street crime. Then, street crime affects students achievement. We observe the change in student achievement during the period of the EBT program implementation.

Some studies have investigated these two affects separately. For the effect of EBT program on street crime, several studies explain that cash is a strong motivation for the street crime (Wright and Topalli (2013); Wright and Decker (1996)). Researchers investigated the crime rate change associated with different payment method. Armey et al. (2014) use a panel data with 70 countries over 6 years to estimate the impact of electronic financial payments on crime. Their results suggest the access to electronic payments deter economic crime. Foley (2011) focuses on welfare payments and illustrates the relationship between welfare payments and the crime rate. Their results show the crime rate is associated with the welfare payment cycles. Our research focuses on the influence of the welfare payment method change to electronic payment. To study the relationship between the EBT program implementation and street crime rate, Wright et al. (2014) use the EBT implementation across Missouri counties to identify a negative and significant effect on the street crime rate. According to their estimates, the street crime rate decreased by 9.8 percent in response to the EBT program.

The change of the SNAP payment method, especially the implementation of the EBT program, impacts the street crime rate. Does street crime rate affects student achievement in these communities? It's clear that school order and safety are very important factors in student achievement. Chen and Weikart (2008) use 613 elementary schools in New York City as their sample to identify this effect. By employing a 
structural model, they confirm the school disorder affects student achievement negatively. Cornell and Mayer (2010) summarized a body of studies to reveal the school violence and disruption has a strong impact on students academic achievement. Beland and Kim (2015) use both school-level and student-level data to identify the student performance reaction to fatal shootings and their results show a negative and statistically significant does impact of students academic achievement from school shootings. Not only does violence and disorder within the schools affect students performance, the violence in their family and community also has a large influence on student performance. Schwab-Stone et al. (1995) link the community violence to lower school academic achievement. Margolin and Gordis (2000) point out one of the cognitive problems of exposure to family and community violence is poor academic achievement. What's more, researchers find family and community violence has a series of consequences, like decrease in enrollment, resultant stress symptoms, and lower graduation rate (Grogger (1997); Beland and Kim (2015);Berman et al. (1996)). The literature above tell us violence in and around schools have negative effects on student achievement.

Although there is a large body of studies focus on these two relationships, however, none of the literature pay attention to the effect of SNAP payment method shifts on students achievement. Kim (2016) uses the EBT program implementation as an instrumental variable to investigate the influence of violent crime on student achievement. This is the first study using the EBT program implementation to investigate students performance. It examines the effect of the crime rate on educational achievement.

We believe other than street crime, the EBT implementation can affect the food supply and nutrition of family. This change can influence the student achievement as well. We believe the direct effect of the EBT program implement on student 
academic achievement is more overwhelming. Our study focus on this direct effect instead of using EBT as an instrument to check the relationship between street crime and educational achievement. This is the first study on the student performance from the point of SNAP payment method shift.

Our study uses the EBT program implement as a shock to examine the effect of SNAP payment method on educational attainment. To identify this effect we use the the EBT program implementation in 114 Missouri counties during 1997 to 1998 as our sample. We use a school-level standard test score in grade 4 and grade 8 to check the differences before and after the EBT program implementation within different groups.

We employ a difference-in-difference method in our study. We use year 1998 as a threshold to check the differences between one group of counties which have already implemented EBT with the other of counties which still used paper checks. The key assumption we have here is the trend of the student performance of these two groups of counties are similar before 1998. There is a challenge we have to face. During 1997 to 1998 the standard test in Missouri public school system was gradually switching from Missouri Mastery and Achievement Tests (MMAT) to Missouri Assessment Program (MAP) tests. We need to isolate the effect of this change. We will discuss this in the following sections.

In the following, we begin by introducing the background of the EBT program implement and standard test in Missouri public school system, then describe the data and empirical methods we apply, section 2.4 presents our robustness results and a concluding discussion in section 2.5. 


\subsection{Background}

In section 2.1 we explained the problem we plan to examine in this study. To employ the difference-in-difference method, there should be an event and two different groups, one is the treated group and the other is the untreated group. In our study the implementation of the EBT program in Missouri State from 1997 to 1998 is the event we adapt to the difference-in-difference model. We will introduce some background information of the event in the following. Then, we will address some background information on the standardized tests in Missouri public schools.

\subsubsection{Implementation of EBT in Missouri}

From the beginning of 1980s, the federal government started to shift SNAP payment method to EBT. In 1996 lawmakers signed the Personal Responsibility and Work Opportunity Reconciliation Act. This Act required every state to implement the EBT program to issue government benefits by 2002 .

To response this reform, Missouri legislators establish an EBT pilot program in Missouri counties with a population of 600,000 or more. The EBT pilot program launched in the middle of 1997. After that the rest of the counties in Missouri state gradually shifted to the EBT program.

Figure B.1 is the EBT implement schedule map for Missouri countries. This is the same map used by Wright et al. (2014). There are eight different groups of counties with different EBT implementation schedule in this map from June 1997 to May 1998. In our study we employ five different groups of counties as sample. The counties with a implementation schedule in 1997 is our treated group. The treated group covers the southern part of the Missouri state and it has 56 counties in total. The group which started to implement EBT program in May 1998 is our untreated group. There are 
44 counties in this group and all of them in the northern part of Missouri state.

We exclude the counties in Saint Louis and Kansas city metropolitan area in our study. In figure B.1 these metropolitan area are labeled as 5, 6, and 7. We want to make sure that at least a five-month gap of the implementation schedule between the treated and untreated group exists. Another reason we exclude these three areas is all of them are metropolitan and in the rest of five areas most of the counties are town or rural areas. The condition of street crime and poverty level are different within these two groups.

\subsubsection{Standard Test in the Missouri Public School System}

During 1997 to 2000, there are two different kinds of standard tests were used in the Missouri public school system, MMAT and MAP tests. MMAT is a criterionreferenced test to measure student progress on specific key skills over time. MMAT tests all the grades from grade 2 to grade 10. For the test contents, MMAT covers mathematics, reading, science, and social studies for all the grads from 1990 to 2000.

To implement the requirements of the Outstanding Schools Act which was passed by the Missouri legislature in 1993, the Department of Elementary and Secondary Education gradually switched from the MMAT test to the MAP test starting in 1997. Unlike the MMAT, which used multiple choice questions only, the MAP test also has short answer and essay questions. The test grade of MAP is from grade 3 to grade 11 except grade 6. Compared with MMAT, MAP test covers more areas, including: Fine Arts and Health. What's more, MMAT tested all the contents in all the grades, but MAP only tested two contents in each grade. For example, in 1999 the grade 8 tests Mathematics and Social Studies, and grade 10 tests Mathematics and Science. 
Most of the transition between these two tests finished in 1997 and 1998. Using the math test in grade 8 as an example, table B.1 represents the number of schools taking these two test during 1995 to 2002. Based on the table we find the transition year began from 1997. In 1997 48.29\% schools took both MMAT and MAP test, $32.52 \%$ schools took MMAT test only, and $18.19 \%$ took the MAP test only. In 1998, only 3 out of 646 schools took MMAT test only, $99.54 \%$ schools took MAP test in that year. From 1999 all the schools took MAP math test in grade 8 .

By using the schools which took both MMAT and MAP in 1997 and 1998 we exam the covariance of the standardized test scores of these two tests. For 1997 the covariance is 0.439 , and 0.446 in 1998 . As we do not have student-level information, it is hard to distinguish the pattern of how schools selected students to take which test. And it is not appropriate to treat MMAT and MAP as the same test. To simplify this problem, we exclude the MMAT test information in our difference-in-difference analysis. We use the MAP math test of grade 4 and grade 8 from 1997 to 2005 as our sample to identify the effect of the EBT program implementation.

\subsection{Empirical Strategy and Data}

In section 2.2 we explain the reason why we prefer to use the math score of grade 4 and grade 8 of MAP test to investigate the effect of welfare payment method shift on student achievement. The focus of this research is to find the differences of the students achievement between the counties with implementation of EBT programs and the counties without in Missouri state around 1998.

Ideally, if we can find some schools and all of them took the same test in one time, then a group of schools take the second test after their counties implementation and the rest of the schools before their implementation day, compare the change of 
the students performance during the two tests and between the two groups of schools can illustrate the effect of the EBT implementation. This is the basic set up of difference-in-difference method we employ.

In this section we briefly introduce the data we investigate, the empirical strategy we employ, and the method we use to improve the identification.

\subsubsection{Data}

As we mention in section 2.2.2 there are two standard tests in the Missouri public school system during 1997 to 2000: MMAT and MAP. We use the school level aggregate data for both the MMAT and MAP tests. By matching the unique school ID we link these two data sets with the school level administration data to access the characteristics of the public schools. All these data are collected by the Missouri Department of Elementary and Secondary Education.

The essential component of this research is the different EBT program implementation schedules in different counties. In section 2.2.1 we explain the treated and untreated group we use in this analysis. Now we need to link the public schools with their county information. Because of the absence of the county information in the administration data, we use Common Core Data $\left(\mathrm{CCD}^{1}\right)$ as a bridge. We manually categorize all the 114 Missouri counties into 8 groups based on the Figure B.1 with group code 1 through 8 by matching the order of the EBT program implementation schedule. The counties which have already implemented the EBT program in 1997 labeled as Group 1 to 4 is our treated group. The counties which did not implement the EBT program until May 1998 are labeled as Group 8 and this is our untreated group. By the county code in CCD we link the public schools with the group code.

\footnotetext{
${ }^{1}$ Common Core of Data (CCD) is a program of the U.S. Department of Education's National Center for Education Statistics that annually collects fiscal and non-fiscal data about all public schools, public school districts and state education agencies in the United States.
} 
Then we link the CCD with the administration data by the unique school code.

Table B.2 and table B.3 represent the summary statistics of the demographic variables in grade 4 and 8 . In these tables we compare the demographic variables of the all the observations and the observations we use as our treated or untreated group. The proportion minority is lower in our treated and untreated group. This is because the samples we exclude are in the Saint Louis metropolitan area and the Kansas city metropolitan area. The ratio of minority is much higher in these metropolitan areas. Our study focuses on the suburbs, towns and rural areas. Taking the high street crime rate in the metropolitan area into account, the result of our study can be a lower bar of the same effect in the metropolitan areas.

By linking different data sets we have 1991 to 1998 school level MMAT math scores with public school information by different grades. For the MAP test the time period is 1997 to 2005. For grade 8 there are 9596 observations for MMAT and MAP test in the time span and 9335 , nearly $97.28 \%$, can be linked with the administration data and a group ID. For grade 4 this ratio is close to $98.50 \%$.

Table B.4 and table B.5 are the comparison of the standardized MAP Math test scores between the treated group and the untreated group in grade 4 and grade 8 . Figure B.2 and figure B.3 are paired with these two tables. These figures illustrate the trend of the mean value of the standardized MAP math score for these 2 groups of schools. For grade 4 in figure B.2, before 1998 the trends of the 2 groups are similar. After 1998, the treated group was more variation. The average score of the untreated group is always higher than the treated group. In the 1998 test, both the treated and untreated group's performance dropped. The degree of the decrease is 0.12 standard deviations for the treated group and 0.18 for untreated group. The decrease for the untreated group is much higher than the treated group. For grade 8, we find in 1998 the mean score of the treated group increase 0.03 compared with the 0.05 decrease of 
the untreated group. To 1999, the mean score of the treated grade keeps increasing while the untreated group keeps decreasing.

One year data of 1997 is not sufficient to illustrate the pre treatment trend. However there is no MAP test before 1997, so we used the standardized MMAT math score from 1991 to 1996 as a substitution of the MAP test score. Based on the schools which took the MAP test in 1997 we check these schools MMAT test score from 1991 to 1996. Meanwhile, we use the 1997 MAP schools as the baseline choose the schools which took MAP during 1998 to 2005. Table B.6 and table B.7 are the comparison of the standardized MAP math test scores during 1997 to 2005, and standardized MMAT math test scores during 1991 to 1996. Both of these are based on the schools which took MAP in 1997. Figure B.4 and figure B.5 are paired with these two tables. From figure B.4, the trend of the average math test score between two groups during the pre-event period has some similarity. However for grade 8 it is really hard to be sure the trends are similar. There are several reasons the pre-event trends may be fluctuating. First of all, MAP and MMAT are different test. The MAP test is more comprehensive than the MMAT. Schools with high scores on the MMAT may not be good at MAP as well. What's more, we choose the MMAT observations conditional on the schools took MAP in 1997. This may create fluctuation in the pre-event trends.

To exclude the variations from sampling of schools taking the MAP test from 1997 to 2005 we select a conditional group of schools that took all the MAP tests in math from 1997 to 2005. The standardized MAP math scores is presented in table B.8 and table B.9. From these two tables we can see for both grade 4 and grade 8 , the mean of the MAP math test score drooped. However, the untreated group had a much larger decrease than the treated group between 1997 and 1998 . We will use Difference-in-Difference method to investigate this in the following section. 


\subsubsection{Difference-in-Difference Model}

Figure B.2 and figure B.3 reveals the different trends of these two groups during the Missouri EBT program implementation. To identify the effect of EBT program on students achievement, we employ a difference-in-difference estimator. As we described, the implementation of the EBT program in Missouri is step by step. By using year 1998 as a threshold, we divide the Missouri counties into two groups. The counties which have already implemented the EBT program in 1997 are our treated group and the counties which haven't implemented the EBT program until May 1998 are our untreated group.

As we stated, the Missouri public school started changing standard test from MMAT to MAP in 1997. By 1998, nearly 95\% was switched to MAP. Among these schools only $30 \%$ is the first time which take MAP. Encountering the MAP test for the first time may induce some identification problems. To eliminate this concern, we use the schools which took all the MAP tests since 1997 to 2005 as a condition. For all the other observations from 1998 to 2005 we filter out the schools which missed any of the MAP tests in this period. With this conditional group we get rid of the effect of the switching tests on student achievement.

Meanwhile, as in 1999 all the schools in these two group had been treated, so all the observations since 1999 to 2005 will be coded as treated group. In the robustness check section we will only use the 1997 and 1998 period to test this effect.

The equation for the difference-in-difference model is,

$$
Y_{j t}=\beta_{0}+\beta_{1} \cdot \text { treat }_{j} \cdot \text { Event }_{j t}+\beta_{2} \cdot \text { Event }_{j t}+X_{j t} \cdot \gamma+\theta_{j}+\epsilon_{j t}
$$

With $Y_{j t}$ : the standardized math test score of school $j$, year $t$. Variable treat ${ }_{j}$ takes a value of 1 when the observation is in treated group and the 0 for the untreated 
group. Event ${ }_{j t}$ takes a value of 1 in year 1998 or later and 0 in year 1997. $X_{j t}$ is a set of control variable including: the log value of the students enrollment in school, the percentage of female student, and the percentage of white students. $\theta_{j}$ represents the school fixed effect, and $\epsilon_{j t}$ is an error term. All the standard errors are clustered at school level.

$\beta_{1}$ is the difference-in-difference estimator we are interested in. Traditionally, to estimate the effect of the event on the treated group by difference-in-difference method, there should be variables of the event dummy and treated group dummy in the regression. In our case, the treated group dummy is collinear with a group of the school fixed effect. Therefore in our regression only the product of the event dummy and treated group dummy is necessary. The estimator $\beta_{1}$ represents the treatment effect of the implementation of EBT program on the students achievement in Missouri public school system.

In the last section we tested the pre-event trends of the MAP test score by substituting the MMAT score. For grade 4 we get a similar trends by this substitution, however this similar trend is not clear for grade 8 . Because the lack of the pre-event data of MAP test it's hard to tell the trends of these two groups. So the key identification assumption in this study is that there exist similar trends in the student MAP test score between the treated group and untreated group before 1997.

Several variations from the original regression are estimated to test the validity of our model. Unlike the standard errors are clustered at the school level in the original regression, in the second regression we cluster the standard errors at the school district level in case there are some unobservable school district characteristics which are correlated with the students achievement may vary with the implementation of the EBT program. In the last regression we cut down the periods to two years: 1997 and 1998. By using this strategy we balance the period before and after event, 
and focus on the short term effect of the event.

We apply two groups of data set to all the three regression. One is the unconditional data which includes all the observations from 1997 to 2005. The other group is the conditional group which using the school took MAP in 1997 as the condition.

\subsection{Difference-in-Difference Model Results}

We employ the difference-in-difference as the identification methodology. Before we present the regression result, we first check the difference-in-difference value of the standardized MAP math test score between the treated and untreated group before and after the event. The results of the unconditional group of grade 4 and 8 are presented in table B.10 and table B.11, the results of the conditional group are presented in table B.13 and table B.14. These tables can give us an overview of the direction and the magnitude of the effect. We represent the regression results presents in table B.12 and table B.15. The fundamental regression is equation 2.1. Then we apply the regression to different group to do the robustness check.

\subsubsection{Results}

Table B.12 shows the regression results by using all the schools which took MAP math test during 1997 to 2005 as the sample. There are two columns in this table. Column with label '4' is the estimate based on the data of grade 4, and column with label ' 8 ' is for grade 8. As we mentioned, the treated group dummy is collinear with a group of the school fixed effect. What we interested in is the variable treat $*$ event. treat $*$ event is the difference-in-difference estimates. It represents the difference of the students performance between the group with EBT implement and the group 
without EBT implement around 1998. For grade 8, the performance of the students in the schools which have already implemented EBT program will increase 0.053 standard deviations compared to the schools that didn't start the implementation at that time. For grade 8 the estimate is 0.024 and this estimate is not statistically significant. The positive estimate indicates the implementation of the EBT program may help students achieve better performance in the MAP math test. When we take a look of the magnitude of the estimate, we find for grade 8 , the magnitude is 0.084 standard deviations, close to a half of the average score of the treated group.

The magnitude of the estimate is very large. Based on the trend of the standardized MAP math test score for grade 4 and 8, we find the key issue is the performance of the untreated group in 1997 is much better than their performance after exposure to the event. For grade 4 the mean value of the untreated group standardized score in 1997 is 0.32 standard deviations, which is twice of the standardized score in 1998 to 2005. For the treated group the difference is much smaller than the untreated group.

The direction and magnitude of the regression results are smaller to the results in table B.10 and table B.11. The results in table B.10 and table B.11 take the difference between the differences of the mean value of the standardized MAP math test score before and after the event of the treated and untreated group. The calculated results in these tables can be an rough estimates of the difference-in-difference regression estimator. Compared with table B.12 we find for both grade 4 and grade 8 the calculated result is larger than the regression estimate. That probably because the calculated results do not take some factors, such as school fix effect, into account.

The estimates of the variable 'Event' are statistically significant for grade 4 in table B.12. The significant result tells us the students performance in 1997 is different with the other observation years for grade 4. This may because 1997 is the first time for students encounter with MAP test, meanwhile it's the first time for the educators 
examine the MAP test. Both of the students and educators are not perfectly prepared with the new test, and this may create difference between this first year results.

Table B.15 presents the estimate results using the conditional sample. The conditional sample uses the schools which took all the MAP math tests as the selection criteria and include the test score from 1998 to 2005 of these schools only. In table B.15 we still test for both grade 4 and grade 8 . The estimate of treat $*$ event is 0.055 for grade 4 , and 0.070 for grade 8 . The estimates of grade 8 are statistially significant. Compared with table B.12 we did not find the magnitude of the effect increased in the condition group. All the standard errors in table B.12 and table B.15 are clustering at school level.

Compared with table B.13 and table B.14, the direction of the regression estimates and the calculated results are the same. The magnitudes are very different. For grade 4, the regression estimate is 0.055 standard deviations, and the calculated result is 0.18 standard deviations. For grade 8, the regression estimate is 0.07 standard deviations, and the calculated result is 0.16 standard deviations. Both of the regression estimates are smaller than the calculated results as we controlled other factors in the regression.

For the unconditional sample, there are about 35\% schools do not take MAP math test in 1997. 1998 is their first time using the new test. This can be an identification problem. The conditional sample helps us get rid of the effect of the first encounter the MAP test in 1998. The results show that the effect from the EBT program implementation keeps same after we take the conditional sample into account.

\subsubsection{Robustness Checks}

In the table B.12 and table B.15 the standard errors of the estimates are cluster in the school level. However, some school factors are not determined by schools, but the 
school district. In some cases the implementation of the EBT program in Missouri may affect some characteristics of school districts, and then affect the student performance. This effect may influence all the schools in the same district. By clustering the standard errors at the school district level, we could eliminate this unobservable change in school district characteristics during the EBT program implementation period.

Table B.16 and table B.17 presents the estimate results with standard errors cluster at school district level for both the conditional and unconditional group. Comparing table B.16 and table B.17 with table B.12 and table B.15, clearly, the estimate of the treat $*$ event does not change. The standard errors in these two tables are greater than the standard errors cluster at the school level. The difference between the standard error clustered at different levels are very minor, 0.01 standard deviations for grade 4 and 0.003 standard deviations for grade 8 . All the estimates of the variable treat $*$ event do not change their significant level .

Because the MAP test launched in 1997, the pre-event period is relatively short compared with the post-event period. It is impossible to extend the pre-event period. What we can do is cut the post-event period at the same length as the pre-event period. As a result, we concentrate the sample on year 1997 and 1998 only. Table B.18 and table B.19 report the estimate after we narrow the sample size to year 1997 and 1998. There is no year dummy variable anymore. We include one more variable 'event' which is equal to 1 when observation year is 1998 , else equal to 0 . The difference between the size of conditional sample and unconditional sample are is small. The unconditional sample only has some more observations which are first time took MAP in 1998 than the conditional sample. That's why most of the estimates are identical between table B.18 and table B.19.

The coefficient of the variable treat * event is 0.124 for grade 4 , and 0.090 for 
grade 8. In this regression we find the estimates in both grade 4 and grade 8 are larger than the estimates in the last section, especially for grade 4. However, teh significant level does not change. One explanation could be in a long run the effect of the EBT implementation decrease as time goes by. So the average effect of a long run is smaller than the effect of a short run.

Based on the all the three regressions with both conditional and unconditional sample the difference-in-difference estimates are statistically significant for grade 8. The magnitude of the estimates are stable cross all the three different regressions. All the result shows that the implementation of the EBT program in Missouri state has a positive effect on students achievement and the magnitude of the effect is at least 0.05 standard deviations compared with the untreated group.

\subsection{Conclusion}

In this paper, we examine the effect of the SNAP payment method change on the student achievement. We use the implementation of the EBT program in Missouri Stat as an event, employ difference-in-difference models to investigate this problem. Both the calculated results and regression estimates show a positive coefficient. This coefficient reveals that the students in the counties that implemented EBT program did better compared with their cohort in the counties that still used paper checks for government benefits.

We use both conditional and unconditional samples to test the effect. The calculated result of the difference-in-difference method is 0.15 standard deviations for grade 4, 0.16 standard deviations for grade 8 of the conditional sample. The magnitude of the regression estimate are smaller than the calculated result. And the estimate are close between the conditional and unconditional sample. The results show that the 
standardized math test score of the students in the counties that had an EBT program is 0.07 standard deviations higher than the students in the counties still using paper check for grade 8 . The magnitude of the effect is large.

Another two regressions are used to check the robustness of the model. The regression cluster on school district level helps us get rid of the unobservable factors within school district characteristics which may affect student achievement. The regression with only 1997 and 1998 two period could be a piece of evidence to support that short pre-event period does not change the validity of our model.

The difference-in-difference estimates capture the effect of the implementation of the EBT program on students achievement in Missouri counties. As we state in section 2.1, less cash in transaction decreases the street crime rate, and enhances the nutrition condition in low-income families. All of these have a positive effect on the student academic achievement in the community. By 2003 all the states change to the EBT, however, transaction with cash is still popular, especially in some low-income neighborhoods. With the development of the innovations in payment technologies, the policy makers can encourage these neighborhoods use electronic transition instead of cash. From our study we know this will help the students do a better job in their academic work. 


\section{Appendix A}

\section{Chapter 1}

\section{A.1 Pictures and Graphs}

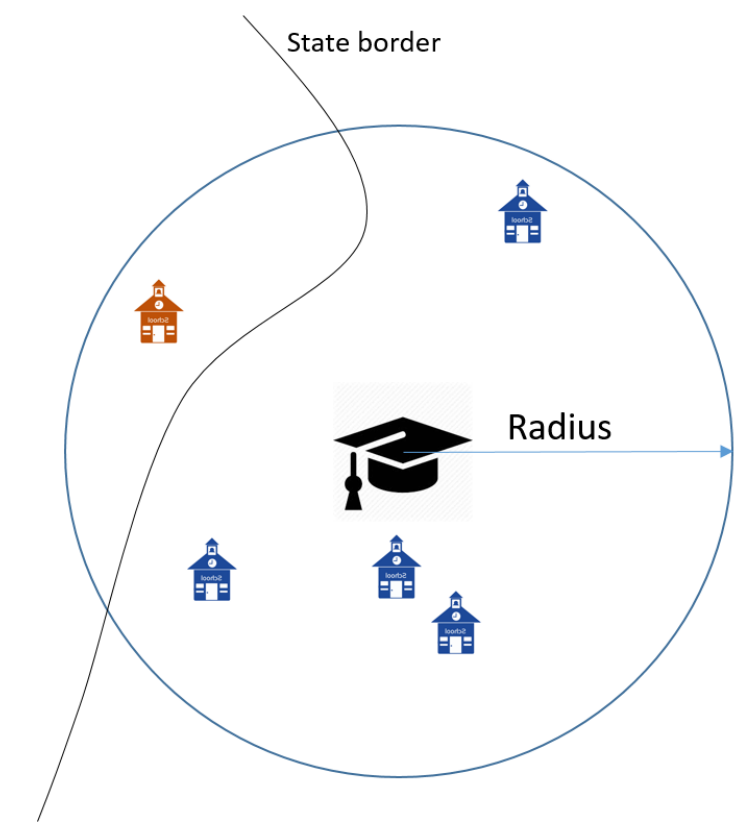

Figure A.1: Local labor market for teachers 


\section{A.2 Tables and Charts}

Table A.1: Cross States Shares by Market Radius distance between college and school

\begin{tabular}{ccccc}
\hline Radius(Miles) & $\mathrm{N}$ & Cross-State & Within-State & Cross-State Pct. \\
\hline \hline $\mathrm{r} \leq 10$ & 303 & 4 & 299 & $1.32 \%$ \\
$10<\mathrm{r} \leq 15$ & 120 & 7 & 113 & $5.83 \%$ \\
$15<\mathrm{r} \leq 30$ & 249 & 14 & 235 & $5.62 \%$ \\
$30<\mathrm{r} \leq 50$ & 192 & 10 & 182 & $5.21 \%$ \\
$\mathrm{r} \leq 50$ & 864 & 35 & 829 & $4.22 \%$ \\
$50<\mathrm{r} \leq 100$ & 306 & 39 & 267 & $12.75 \%$ \\
$100<\mathrm{r} \leq 150$ & 156 & 29 & 127 & $18.59 \%$ \\
$150<\mathrm{r} \leq 200$ & 91 & 33 & 58 & $36.26 \%$ \\
\hline $\mathrm{r}>200$ & 433 & 361 & 72 & $83.37 \%$ \\
Total & 1850 & 497 & 1353 & $36.73 \%$ \\
\hline \hline
\end{tabular}

Note: $\mathrm{N}$ is the number of teacher whose geospatial distance between TPP and school is within this radius category. Cross-state is the number of teacher whose state of school is not same as the state of the college. Within-state is the number of teacher whose state of school is same as the state of the college. Cross-State Pct. is the percentage value using Cross-State divided by N.

Table A.2: Comparison of The Cross State Shares with Prediction Value by Market Radius

\begin{tabular}{cccccc}
\hline Radius & $\mathrm{N}$ & Cross-State-Pct & Prediction & Diff & t-value \\
\hline \hline $\mathrm{r} \leq 10$ & 303 & $1.32 \%$ & $3.64 \%$ & $-2.32 \% * * *$ & -3.532 \\
$10<\mathrm{r} \leq 15$ & 120 & $5.83 \%$ & $7.36 \%$ & $-1.53 \%$ & -0.711 \\
$15<\mathrm{r} \leq 30$ & 249 & $5.62 \%$ & $12.41 \%$ & $-6.79 \% * * *$ & -4.640 \\
$30<\mathrm{r} \leq 50$ & 192 & $5.21 \%$ & $21.16 \%$ & $-15.95 \% * * *$ & -9.922 \\
\hline $50<\mathrm{r} \leq 100$ & 306 & $12.75 \%$ & $39.37 \%$ & $-26.62 \% * * *$ & -13.819 \\
$100<\mathrm{r} \leq 150$ & 156 & $18.59 \%$ & $55.45 \%$ & $-36.86 \% * * *$ & -11.796 \\
$150<\mathrm{r} \leq 200$ & 91 & $36.26 \%$ & $65.38 \%$ & $-29.12 \% * * *$ & -5.745 \\
\hline \hline
\end{tabular}

Note: $\mathrm{N}$ and Cross-State-Pct are identical with Table 1. Prediction is a percentage value using the number of teachers who is in another state compared with the TPP's state within the radius divided by the total number of teacher within the radius. Diff is the difference using Cross-State-Pct minus the Prediction.

Significant level: $* * * \mathrm{p}<0.01,{ }^{* *} \mathrm{p}<0.05,{ }^{*} \mathrm{p}<0.1$ 
Table A.3: Results of the Linear Regressions

\begin{tabular}{|c|c|c|c|c|c|}
\hline \multicolumn{6}{|l|}{ A. Full Sample } \\
\hline Variable & Statistics & 10 miles & 15 miles & 30 miles & 50 miles \\
\hline \multirow{2}{*}{ Cross-State Demand } & Estimate & 0.08916 & $0.08231^{* *}$ & 0.00755 & $0.01144^{*}$ \\
\hline & Std & $(0.06961)$ & $(0.03386)$ & $(0.01127)$ & $(0.00681)$ \\
\hline $\mathrm{N}=1808$ & Mean & 0.15639 & 0.38716 & 1.75442 & 4.74336 \\
\hline Total Demand & $\begin{array}{l}\text { Estimate } \\
\text { Std }\end{array}$ & $\begin{array}{l}-0.03613^{* *} \\
(0.01425)\end{array}$ & $\begin{array}{l}-0.02305^{* * *} \\
(0.00864)\end{array}$ & $\begin{array}{l}-0.00362 \\
(0.00452)\end{array}$ & $\begin{array}{l}-0.00437 \\
(0.00318)\end{array}$ \\
\hline $\mathrm{N}=1808$ & Mean & 2.96247 & 4.89682 & 11.1528 & 20.1574 \\
\hline \multicolumn{6}{|c|}{ B. Public College Fixed Effect } \\
\hline Variable & Statistics & 10 miles & 15 miles & 30 miles & 50 miles \\
\hline Cross-State Demand & $\begin{array}{l}\text { Estimate } \\
\text { Std }\end{array}$ & $\begin{array}{l}0.09329 \\
(0.06075)\end{array}$ & $0.08485^{* *}$ & 0.008073 & $0.01157^{* * *}$ \\
\hline $\mathrm{N}=1808$ & Mean & 0.15639 & 0.38716 & 1.75442 & 4.74336 \\
\hline Total Demand & $\begin{array}{l}\text { Estimate } \\
\text { Std }\end{array}$ & $\begin{array}{l}-0.037249^{* * *} \\
(0.01430)\end{array}$ & $\begin{array}{l}-0.02395^{* * *} \\
(0.00868)\end{array}$ & $\begin{array}{l}-0.00394 \\
(0.00453)\end{array}$ & $\begin{array}{c}-0.004559 \\
(0.00318)\end{array}$ \\
\hline $\mathrm{N}=1808$ & Mean & 2.9624 & 4.8968 & 11.1528 & 20.1574 \\
\hline \multicolumn{6}{|c|}{ C. Private College Graduate } \\
\hline Variable & Statistics & 10 miles & 15 miles & 30 miles & 50 miles \\
\hline \multirow{2}{*}{$\begin{array}{l}\text { Cross-State Demand } \\
\qquad \mathrm{N}=474\end{array}$} & Estimate & 0.25260 & 0.01660 & 0.01862 & 0.01011 \\
\hline & Std & $(0.16493)$ & $(0.02443)$ & $(0.01330)$ & $(0.005940)$ \\
\hline $\mathrm{N}=474$ & Mean & 0.04001 & 0.08700 & 0.73860 & 4.00473 \\
\hline \multirow{2}{*}{ Total Demand } & Estimate & -0.00493 & -0.00241 & -0.00439 & -0.00203 \\
\hline & Std & $(0.02477)$ & $(0.01456)$ & $(0.00890)$ & $(0.00647)$ \\
\hline $\mathrm{N}=474$ & Mean & 0.36971 & 0.67386 & 1.3306 & 2.11900 \\
\hline \multicolumn{6}{|c|}{ D. Less Selective College } \\
\hline Variable & Statistics & 10 miles & 15 miles & 30 miles & 50 miles \\
\hline \multirow{3}{*}{$\begin{array}{l}\text { Cross-State Demand } \\
\qquad \mathrm{N}=1628\end{array}$} & Estimate & 0.08873 & $0.07807^{* *}$ & 0.01249 & 0.00983 \\
\hline & Std & $(0.07469)$ & $(0.03564)$ & (0.01203) & $(0.00703)$ \\
\hline & Mean & 0.14472 & 0.36513 & 1.66809 & 4.33697 \\
\hline \multirow{2}{*}{ Total Demand } & Estimate & $-0.03977^{* * *}$ & $-0.02264^{* *}$ & -0.00569 & -0.00492 \\
\hline & Std & $(0.01474)$ & $(0.00895)$ & $(0.00477)$ & $(0.00336)$ \\
\hline $\mathrm{N}=1628$ & Mean & 2.84443 & 4.68840 & 10.4614 & 18.6245 \\
\hline \multicolumn{6}{|l|}{ E. STEM teachers } \\
\hline Variable & Statistics & 10 miles & 15 miles & 30 miles & 50 miles \\
\hline \multirow{2}{*}{ Cross-State Demand } & Estimate & 0.10009 & 0.00750 & 0.01285 & 0.02979 \\
\hline & Std & $(0.26809)$ & $(0.12858)$ & (0.03698) & $(0.01793)$ \\
\hline $\mathrm{N}=366$ & Mean & 0.08086 & 0.21152 & 1.20859 & 4.32239 \\
\hline Total Demand & $\begin{array}{c}\text { Estimate } \\
\text { Std }\end{array}$ & -0.00544 & $\begin{array}{l}0.00037 \\
(0.02415)\end{array}$ & $\begin{array}{l}0.00889 \\
(0.01159)\end{array}$ & -0.00194 \\
\hline $\mathrm{N}=366$ & Mean & 2.83295 & 4.58906 & 10.4243 & 19.9569 \\
\hline
\end{tabular}

Table A.3 reports the estimates of the 'Cross state demand' and 'Total demand' in different linear regressions. ${ }^{* * * *} \mathrm{p}<0.001,{ }^{* * *} \mathrm{p}<0.01,{ }^{* *} \mathrm{p}<0.05,{ }^{*} \mathrm{p}<0.1$ 
Table A.4: Number of Alternatives by Market Radius

\begin{tabular}{cccc}
\hline & 50 miles & 100 miles & 200 miles \\
\hline \hline Size & 842 & 1141 & 1381 \\
Median & 296 & 1043 & 3733 \\
Mean & 616 & 1512 & 4460 \\
\hline \hline
\end{tabular}

Note: Size is the number of teachers who choose to teach in a public school within this radius category. Median is the median of the total number of the public schools within the radius. Mean is the average of the total number of the public schools within the radius.

Table A.5: Range of the Estimates for 50 Miles Radius Group

\begin{tabular}{|c|c|c|c|c|c|c|c|}
\hline \multirow{2}{*}{ Variable } & \multirow{2}{*}{ Statistics } & \multicolumn{2}{|c|}{10 Choices } & \multicolumn{2}{|c|}{15 Choices } & \multicolumn{2}{|c|}{20 Choices } \\
\hline & & Minimum & Maximum & Minimum & Maximum & Minimum & Maximum \\
\hline \multirow{3}{*}{$\begin{array}{l}\ln (\operatorname{dist} 1) \\
\operatorname{dist} \leq 25\end{array}$} & Estimate & $-.33763^{* * * *}$ & $-.18154^{* *}$ & $-.29076^{* * * *}$ & $-.19761^{* * *}$ & $-.28950^{* * * *}$ & $-.20274^{* * * *}$ \\
\hline & Std Error & $(0.0561)$ & $(0.0571)$ & $(0.0543)$ & $(0.0526)$ & $(0.0540)$ & $(0.0517)$ \\
\hline & Odds Ratio & 0.71346 & 0.83398 & 0.74769 & 0.82069 & 0.74863 & 0.81649 \\
\hline \multirow{3}{*}{$\begin{array}{c}\ln (\text { dist } 2) \\
25<\text { dist }<50\end{array}$} & Estimate & -.49138**** & $-.39342^{* * * *}$ & $-.47093^{* * * *}$ & $-.39599^{* * * *}$ & $-.46989^{* * * * *}$ & $-.40562^{* * * *}$ \\
\hline & Std Error & $(0.0420)$ & $(0.0423)$ & $(0.0402)$ & $(0.0392)$ & $(0.0388)$ & (0.0398) \\
\hline & Odds Ratio & 0.61178 & 0.67475 & 0.62442 & 0.67302 & 0.62507 & 0.66656 \\
\hline \multirow{3}{*}{ Cross } & Estimate & $-1.8851^{* * * *}$ & $-1.4768^{* * * *}$ & $-1.8614^{* * * *}$ & $-1.5322^{* * * *}$ & $-1.8362^{* * * *}$ & $-1.5981^{* * * *}$ \\
\hline & Std Error & $(0.2234)$ & $(0.2072)$ & $(0.2036)$ & $(0.2043)$ & $(0.1946)$ & $(0.1976)$ \\
\hline & Odds Ratio & 0.15182 & 0.22837 & 0.15545 & 0.21605 & 0.15942 & 0.20228 \\
\hline \multirow{3}{*}{ Size } & Estimate & $0.01837^{* * * *}$ & $0.02488^{* * * * *}$ & $0.01808 * * * *$ & $0.02226^{* * * *}$ & $0.01820^{* * * *}$ & $0.02191^{* * * *}$ \\
\hline & Std Error & $(0.0010)$ & $(0.0015)$ & $(0.0009)$ & $(0.0013)$ & $(0.0009)$ & $(0.0012)$ \\
\hline & Odds Ratio & 0.91854 & 0.92519 & 0.91824 & 0.92251 & 0.91837 & 0.92216 \\
\hline \multirow{3}{*}{ NSLP } & Estimate & -0.19578 & 0.24892 & -0.1388 & 0.23143 & -0.08919 & 0.18192 \\
\hline & Std Error & $(0.2082)$ & $(0.2110)$ & $(0.2071)$ & $(0.2057)$ & $(0.2049)$ & $(0.2038)$ \\
\hline & Odds Ratio & 0.82219 & 0.88264 & 0.87041 & 0.86041 & 0.91467 & 0.99952 \\
\hline \multirow{3}{*}{ Minority } & Estimate & 0.24159 & $0.61074^{* *}$ & 0.23784 & $0.58189^{* *}$ & 0.26255 & $0.54694^{* *}$ \\
\hline & Std Error & $(0.1950)$ & $(0.1976)$ & $(0.1889)$ & (0.1927) & $(0.1845)$ & $(0.1879)$ \\
\hline & Odds Ratio & 0.87327 & 0.8418 & 0.26851 & 0.78941 & 0.70024 & 0.72796 \\
\hline \multirow{3}{*}{ Pupil/Teacher } & Estimate & -0.00042 & $0.01397^{*}$ & -0.00048 & 0.01229 & 0.00003 & 0.00657 \\
\hline & Std Error & $(0.0062)$ & $(0.0069)$ & $(0.0060)$ & $(0.0064)$ & $(0.0049)$ & $(0.0038)$ \\
\hline & Odds Ratio & 0.99958 & 0.91407 & 0.99952 & 0.91237 & 0.99003 & 0.99659 \\
\hline
\end{tabular}

Notes: Table A.5 reports the range of the estimates of a mixed logit model with different size of choices which are within 50 miles from the TPP. For each choice size I report the minimum and maximum of the estimate with the standard error and odds ratio by ranking the magnitude of the estimates. The standard error is a combination of the standard error of the regression and the standard error of the 101 estimates in one group. $* * * * \mathrm{p}<0.001, * * * \mathrm{p}<0.01, * * \mathrm{p}<0.05, * \mathrm{p}<0.1$ 
Table A.6: Range of the Estimates for 100 Miles Radius Group

\begin{tabular}{|c|c|c|c|c|c|c|c|}
\hline \multirow{2}{*}{ Variable } & \multirow{2}{*}{ Statistics } & \multicolumn{2}{|c|}{10 Choices } & \multicolumn{2}{|c|}{15 Choices } & \multicolumn{2}{|c|}{20 Choices } \\
\hline & & Minimum & Maximum & Minimum & Maximum & Minimum & Maximum \\
\hline \multirow{3}{*}{$\begin{array}{l}\ln (\operatorname{dist} 1) \\
\operatorname{dist} \leq 25\end{array}$} & Estimate & $-.35365 * * * *$ & $-.14105^{*}$ & $-.30902^{* * * *}$ & $-.16516^{* *}$ & $-.29183^{* * * *}$ & $-.17908^{* * *}$ \\
\hline & Std Error & $(0.0641)$ & $(0.0596)$ & $(0.0567)$ & $(0.0544)$ & $(0.0537)$ & $(0.0517)$ \\
\hline & Odds Ratio & 0.70212 & 0.86845 & 0.73416 & 0.84776 & 0.74689 & 0.83604 \\
\hline \multirow{3}{*}{$\begin{array}{c}\ln (\operatorname{dist} 2) \\
25<\text { dist } \leq 50\end{array}$} & Estimate & $-.49930 * * * *$ & $-.35470^{* * * *}$ & $-.48264^{* * * *}$ & $-.36216^{* * * *}$ & $-.46352^{* * * *}$ & $-.36697^{* *}$ \\
\hline & Std Error & $(0.0486)$ & $(0.0450)$ & $(0.0427)$ & $(0.0411)$ & $(0.0407)$ & $(0.0393)$ \\
\hline & Odds Ratio & 0.60695 & 0.70138 & 0.61715 & 0.69617 & 0.62907 & 0.69283 \\
\hline \multirow{3}{*}{$\begin{array}{c}\ln (\text { dist } 3) \\
50<\text { dist } \leq 75\end{array}$} & Statistics & $-.62326^{* * * *}$ & $-.50450^{* * * *}$ & $-.60218^{* * * *}$ & $-.49374^{* * * *}$ & $-.60419^{* * * *}$ & $-.52430^{* * * *}$ \\
\hline & Estimate & $(0.0442)$ & $(0.0408)$ & $(0.0395)$ & $(0.0376)$ & $(0.0373)$ & $(0.0362)$ \\
\hline & Std Error & 0.53619 & 0.60381 & 0.54762 & 0.61034 & 0.54652 & 0.59197 \\
\hline \multirow{3}{*}{$\begin{array}{c}\ln (\text { dist } 4) \\
75<\text { dist } \leq 100\end{array}$} & Statistics & $-.66547 * * * *$ & $-.54508^{* * * *}$ & $-.64407^{* * * *}$ & $-.54242^{* * * *}$ & $-.64287^{* * * *}$ & $-.55853^{* * * *}$ \\
\hline & Esti & $(0.0430)$ & $(0.0387)$ & $(0.0381)$ & $(0.0357)$ & $(0.0358)$ & $(0.0349)$ \\
\hline & Std Error & 0.51403 & 0.5798 & 0.52515 & 0.58134 & 0.52578 & 0.57205 \\
\hline \multirow{3}{*}{ Cross } & Estimate & $-1.9825^{* * * *}$ & $-1.6736^{* * * *}$ & $-1.9649^{* * * *}$ & $-1.6943^{* * * *}$ & $-1.9310^{* * * *}$ & $-1.7632^{* * * *}$ \\
\hline & Std Error & $(0.1489)$ & $(0.1462)$ & $(0.1425)$ & $(0.1385)$ & $(0.1437)$ & $(0.1402)$ \\
\hline & Odds Ratio & 0.13773 & 0.187 & 0.14016 & 0.18373 & 0.145 & 0.1715 \\
\hline \multirow{3}{*}{ Size } & Estimate & $0.01838 * * * *$ & $0.02304^{* * * *}$ & 0.01760 ***** & $0.02179 * * * *$ & $0.01798^{* * * *}$ & $0.02187^{* * * *}$ \\
\hline & Std Error & $(0.0010)$ & $(0.0013)$ & $(0.0010)$ & $(0.0012)$ & $(0.0008)$ & $(0.0011)$ \\
\hline & Odds Ratio & 0.91855 & 0.923 & 0.91776 & 0.92203 & 0.91814 & 0.92211 \\
\hline \multirow{3}{*}{ NSLP } & stimate & -0.27753 & 0.1639 & -0.21056 & 0.07765 & -0.22901 & 0.03983 \\
\hline & Std Error & $(0.1874)$ & $(0.1892)$ & $(0.1769)$ & $(0.1785)$ & $(0.1729)$ & $(0.1761)$ \\
\hline & Odds Ratio & 0.75765 & 0.9782 & 0.81013 & 0.98074 & 0.79532 & 0.94064 \\
\hline \multirow{3}{*}{ Minority } & Estimate & 0.23992 & $0.58984^{* * * *}$ & 0.24872 & $0.52529 * *$ & 0.25589 & $0.49371^{* *}$ \\
\hline & Std Error & $(0.1707)$ & & & & & $(0.1584)$ \\
\hline & Odds Ratio & 0.87115 & 0.8037 & 0.88238 & 0.99096 & 0.89161 & 0.93838 \\
\hline \multirow{3}{*}{ Pupil/Teacher } & Estimate & -0.00105 & $0.01882^{*}$ & -0.00004 & 0.01267 & -0.00047 & 0.00759 \\
\hline & & $(0.0045)$ & $(0.0075)$ & $(0.0048)$ & $(0.0067)$ & $(0.0037)$ & $(0.0044)$ \\
\hline & Odds Ratio & 0.99895 & 0.919 & 0.99996 & 0.91275 & 0.99953 & 0.99762 \\
\hline
\end{tabular}

Notes: Table A.6 reports the range of the estimates of a mixed logit model with different size of choices which are within 100 miles from the TPP. For each choice size I report the minimum and maximum of the estimate with the standard error and odds ratio by ranking the magnitude of the estimates. The standard error is a combination of the standard error of the regression and the standard error of the 101 estimates in one group. $* * * * \mathrm{p}<0.001,{ }^{* * *} \mathrm{p}<0.01,{ }^{* *} \mathrm{p}<0.05,{ }^{*} \mathrm{p}<0.1$ 
Table A.7: Range of the Estimates for 200 Miles Radius Group

\begin{tabular}{|c|c|c|c|c|c|c|c|}
\hline \multirow{2}{*}{ Variable } & \multirow{2}{*}{ Statistics } & \multicolumn{2}{|c|}{10 Choices } & \multicolumn{2}{|c|}{15 Choices } & \multicolumn{2}{|c|}{20 Choices } \\
\hline & & Minimum & Maximum & Minimum & Maximum & Minimum & Maximum \\
\hline \multirow{3}{*}{$\begin{array}{l}\ln (\operatorname{dist} 1) \\
\operatorname{dist} \leq 25\end{array}$} & Estimate & $-.42813^{* * * *}$ & -0.14745 & $-.45076^{* * * *}$ & $-.17517^{* *}$ & $-.37959^{* * * *}$ & $-.15697^{*}$ \\
\hline & Std Error & $(0.0860)$ & $(0.0799)$ & $(0.0723)$ & $(0.0662)$ & $(0.0662)$ & $(0.0616)$ \\
\hline & Odds Ratio & 0.65173 & 0.86291 & 0.63714 & 0.83931 & 0.68414 & 0.85473 \\
\hline \multirow{3}{*}{$\begin{array}{c}\ln (\text { dist } 2) \\
25<\text { dist } \leq 50\end{array}$} & Estimate & $-.56915^{* * * *}$ & $-.37987^{* * * *}$ & $-.56743^{* * * * *}$ & $-.37587 * * * *$ & $-.53760^{* * * *}$ & $-.37526^{* * * *}$ \\
\hline & Std Error & $(0.0607)$ & $(0.0569)$ & $(0.0547)$ & $(0.0521)$ & $(0.0493)$ & $(0.0461)$ \\
\hline & Odds Ratio & 0.56601 & 0.68395 & 0.56698 & 0.68669 & 0.58415 & 0.68711 \\
\hline \multirow{3}{*}{$\begin{array}{c}\ln (\operatorname{dist} 3) \\
50<\operatorname{dist} \leq 75\end{array}$} & Statistics & $-.66604^{* * * *}$ & $-.50612^{* * * *}$ & $-.67515^{* * * *}$ & $-.49338^{* * * *}$ & $-.64840^{* * * *}$ & $-.51077^{* * * *}$ \\
\hline & & $(0.0554)$ & $(0.0499)$ & $(0.0488)$ & $(0.0460)$ & $(0.0453)$ & $(0.0431)$ \\
\hline & Std E & 0.51374 & 0.60283 & 0.50908 & 0.61056 & 0.52288 & 0.60003 \\
\hline \multirow{3}{*}{$\begin{array}{c}\ln (\text { dist } 4) \\
75<\text { dist } \leq 100\end{array}$} & Statis & $-.69951^{* * * *}$ & $-.53199 * * * *$ & $-.69993^{* * * *}$ & $-.56526^{* * * *}$ & $-.68190^{* * * *}$ & $-.54203^{* * * *}$ \\
\hline & Estil & $(0.0529)$ & $(0.0464)$ & $(0.0476)$ & $(0.0444)$ & $(0.0420)$ & $(0.0395)$ \\
\hline & Std E & 0.49683 & 0.58743 & 0.49662 & 0.568 & 0.50565 & 0.58157 \\
\hline \multirow{3}{*}{$\begin{array}{c}\ln (\text { dist } 5) \\
100<\text { dist } \leq 150\end{array}$} & Estim & $-.77866^{* * * *}$ & $-.63870^{* * * *}$ & $-.78723^{* * * *}$ & $-.65420^{* * * *}$ & $-.76244^{* * * *}$ & $-.64134^{* * * *}$ \\
\hline & & $(0.0477)$ & $(0.0421)$ & $(0.0412)$ & $(0.0389)$ & $(0.0389)$ & $(0.0363)$ \\
\hline & Odds Ratio & 0.45902 & 0.52798 & 0.4551 & 0.51986 & 0.46652 & 0.52659 \\
\hline \multirow{3}{*}{$\begin{array}{c}\ln (\text { dist } 6) \\
150<\text { dist } \leq 200\end{array}$} & Estimate & $-.84084^{* * * *}$ & $-.70132^{* * * *}$ & $-.83397^{* * * *}$ & $-.71743^{* * * *}$ & $-.81653^{* * * *}$ & $-.69658^{* * * *}$ \\
\hline & & $(0.0464)$ & $(0.0419)$ & $(0.0414)$ & (0.03 & & $(0.0364)$ \\
\hline & Odds Ratio & 0.43135 & 0.49593 & 0.43432 & 0.488 & 0.44196 & 0.49829 \\
\hline \multirow{3}{*}{ Cross } & Estimate & $-1.9960^{* * * *}$ & $-1.8160^{* * * *}$ & $-2.0171^{* * * *}$ & $-1.8441^{* * * *}$ & $-2.0284^{* * * *}$ & $-1.8463^{* * * *}$ \\
\hline & Std Error & $(0.1221)$ & $(0.1169)$ & $(0.1159)$ & $(0.1115)$ & $(0.1132)$ & $(0.1117)$ \\
\hline & Odds Ratio & 0.13588 & 0.162 & 0.13304 & 0.15 & 0.13155 & 0.15781 \\
\hline \multirow{3}{*}{ Size } & & $0.01700^{* * * * *}$ & $0.02349 * * * *$ & $0.01760^{* * * *}$ & $0.02219 * * * *$ & $0.01798^{* * * *}$ & $0.02200^{* * * *}$ \\
\hline & Std Error & $(0.0009)$ & $(0.0014)$ & $(0.0008)$ & $(0.00$ & $(0.0008)$ & $(0.0011)$ \\
\hline & Odds Ratio & 0.91715 & 0.92376 & 0.91775 & 0.92243 & 0.91814 & 0.92225 \\
\hline \multirow{3}{*}{ NSLP } & Estimate & -0.32334 & 0.13761 & -0.28055 & 0.01403 & $-.34831^{*}$ & 0.03828 \\
\hline & & & & & & & \\
\hline & Odds Ratio & 0.72373 & 0.94753 & 0.75537 & 0.91413 & 0.70588 & 0.93902 \\
\hline \multirow{3}{*}{ Minority } & Estimate & 0.15125 & $0.52383^{* *}$ & 0.16009 & $0.51597^{* *}$ & 0.16559 & $0.50043^{* * *}$ \\
\hline & Std Error & $(0.1707)$ & $(0.1687)$ & $(0.1581)$ & $(0.1585)$ & $(0.1558)$ & $(0.1516)$ \\
\hline & Odds Ratio & 0.16328 & & & & 0.18009 & 0.64 \\
\hline \multirow{3}{*}{ Pupil/Teacher } & Estimate & -0.00183 & 0.01371 & -0.00143 & 0.01073 & -0.00109 & 0.00908 \\
\hline & Std Error & $(0.0077)$ & $(0.0076)$ & $(0.0036)$ & $(0.0060)$ & $(0.0028)$ & $(0.0053)$ \\
\hline & Odds Ratio & 0.99817 & 0.91381 & 0.99857 & 0.91079 & 0.99891 & 0.99912 \\
\hline
\end{tabular}

Notes: Table A.7 reports the range of the estimates of a mixed logit model with different size of choices which are within 200 miles from the TPP. For each choice size I report the minimum and maximum of the estimate with the standard error and odds ratio by ranking the magnitude of the estimates. The standard error is a combination of the standard error of the regression and the standard error of the 101 estimates in one group. $* * * * \mathrm{p}<0.001,{ }^{*} * * \mathrm{p}<0.01,{ }^{*} * \mathrm{p}<0.05, * \mathrm{p}<0.1$ 
Table A.8: The Median of the Estimates of 50 Miles Radius Group

\begin{tabular}{cc|lll}
\hline \hline Variable & Statistics & 10 Choices & 15 Choices & 20 Choices \\
\hline \multirow{2}{*}{$\ln ($ dist1) } & Estimate & $-.25360^{* * * *}$ & $-.24798^{* * * *}$ & $-.24697^{* * * *}$ \\
dist $\leq 25$ & Std Error & $(0.0570)$ & $(0.0541)$ & $(0.0516)$ \\
& Odds Ratio & -0.224 & -0.21962 & -0.21884 \\
\hline \multirow{2}{*}{$\ln ($ dist2) } & Estimate & $-.44311^{* * * *}$ & $-.44140^{* * * *}$ & $-.43815^{* * * *}$ \\
$25<$ dist $\leq 50$ & Std Error & $(0.0422)$ & $(0.0390)$ & $(0.0389)$ \\
& Odds Ratio & -0.35796 & -0.35687 & -0.35477 \\
\hline \multirow{5}{*}{ Cross } & Estimate & $-1.7073^{* * * *}$ & $-1.7047^{* * * *}$ & $-1.7349^{* * * *}$ \\
& Std Error & $(0.2101)$ & $(0.1968)$ & $(0.2009)$ \\
& Odds Ratio & -0.81864 & -0.81817 & -0.82358 \\
\hline \multirow{5}{*}{ Size } & Estimate & $0.02082^{* * * *}$ & $0.02062^{* * * *}$ & $0.02020^{* * * *}$ \\
& Std Error & $(0.0014)$ & $(0.0012)$ & $(0.0011)$ \\
& Odds Ratio & 0.02104 & 0.02083 & 0.0204 \\
\hline \multirow{4}{*}{ NSLP } & Estimate & 0.02239 & 0.01678 & 0.00417 \\
& Std Error & $(0.2125)$ & $(0.2076)$ & $(0.2028)$ \\
& Odds Ratio & 0.02264 & 0.01693 & 0.00418 \\
\hline \multirow{2}{*}{ Minority } & Estimate & $0.41806^{*}$ & $0.41954^{*}$ & $0.42046^{*}$ \\
& Std Error & $(0.2026)$ & $(0.1934)$ & $(0.1876)$ \\
& Odds Ratio & 0.51902 & 0.52126 & 0.52266 \\
\hline \multirow{2}{*}{ Pupil/Teacher } & Estimate & 0.0022 & 0.00172 & 0.00186 \\
& Std Error & $(0.0050)$ & $(0.0056)$ & $(0.0062)$ \\
& Odds Ratio & 0.0022 & 0.00172 & 0.00187 \\
\hline \hline
\end{tabular}

Notes: Table A.8 reports the median of the estimates with the standard error and odds ratio of a mixed logit model with different size of choices which are within 50 miles from the TPP. The standard error is a combination of the standard error of the regression and the standard error of the 101 estimates in one group. ${ }^{* * * *} \mathrm{p}<0.001,{ }^{* * *} \mathrm{p}<0.01,{ }^{* *} \mathrm{p}<0.05,{ }^{*} \mathrm{p}<0.1$ 
Table A.9: The Median of the Estimates of 100 Miles Radius Group

\begin{tabular}{cc|lll}
\hline \hline Variable & Statistics & 10 Choices & 15 Choices & 20 Choices \\
\hline \multirow{2}{*}{$\ln ($ dist1) } & Estimate & $-.24773^{* * * *}$ & $-.23488^{* * * *}$ & $-.23505^{* * * *}$ \\
dist $\leq 25$ & Std Error & $(0.0602)$ & $(0.0557)$ & $(0.0538)$ \\
& Odds Ratio & 0.78057 & 0.79066 & 0.79053 \\
\hline \multirow{2}{*}{$\ln ($ dist2) } & Estimate & $-.42287^{* * * *}$ & $-.41859^{* * * *}$ & $-.41794^{* * * *}$ \\
$25<$ dist $\leq 50$ & Std Error & $(0.0452)$ & $(0.0424)$ & $(0.0396)$ \\
& Odds Ratio & 0.65516 & 0.65797 & 0.6584 \\
\hline \multirow{2}{*}{$\ln ($ dist3) } & Estimate & $-.55952^{* * * *}$ & $-.55934^{* * * *}$ & $-.55721^{* * * *}$ \\
$50<$ dist $\leq 75$ & Std Error & $(0.0419)$ & $(0.0393)$ & $(0.0360)$ \\
& Odds Ratio & 0.57148 & 0.57159 & 0.57281 \\
\hline \multirow{2}{*}{$\ln ($ dist4) } & Estimate & $-.60163^{* * * *}$ & $-.60185^{* * * *}$ & $-.59941^{* * * *}$ \\
$75<$ dist $\leq 100$ & Std Error & $(0.0385)$ & $(0.0374)$ & $(0.0356)$ \\
& Odds Ratio & 0.54792 & 0.5478 & 0.54913 \\
\hline \multirow{3}{*}{ Cross } & Estimate & $-1.8142^{* * * *}$ & $-1.8359^{* * * *}$ & $-1.8359^{* * * *}$ \\
& Std Error & $(0.1472)$ & $(0.1400)$ & $(0.1374)$ \\
& Odds Ratio & 0.16296 & 0.15947 & 0.15947 \\
\hline \multirow{2}{*}{ Size } & Estimate & $0.02066^{* * * *}$ & $0.02015^{* * * * *}$ & $0.02010^{* * * *}$ \\
& Std Error & $(0.0013)$ & $(0.0011)$ & $(0.0010)$ \\
& Odds Ratio & 0.92087 & 0.92035 & 0.9203 \\
\hline \multirow{2}{*}{ NSLP } & Estimate & -0.09085 & -0.08753 & -0.08344 \\
& Std Error & $(0.1888)$ & $(0.1801)$ & $(0.1769)$ \\
& Odds Ratio & 0.91315 & 0.91619 & 0.91994 \\
\hline \multirow{2}{*}{ Minority } & Estimate & $0.40427^{*}$ & $0.37581^{*}$ & $0.38420^{*}$ \\
& Std Error & $(0.1690)$ & $(0.1654)$ & $(0.1589)$ \\
& Odds Ratio & 0.49821 & 0.45617 & 0.46843 \\
\hline \multirow{2}{*}{ Pupil/Teacher } & Estimate & 0.00189 & 0.00223 & 0.0019 \\
& Std Error & $(0.0058)$ & $(0.0052)$ & $(0.0054)$ \\
& Odds Ratio & 0.90189 & 0.90223 & 0.90191 \\
\hline \hline \multirow{2}{*}{ Table } & & & &
\end{tabular}

Notes: Table A.9 reports the median of the estimates with the standard error and odds ratio of a mixed logit model with different size of choices which are within 100 miles from the TPP. The standard error is a combination of the standard error of the regression and the standard error of the 101 estimates in one group. ${ }^{* * * *} \mathrm{p}<0.001,{ }^{* * *} \mathrm{p}<0.01,{ }^{* *} \mathrm{p}<0.05,{ }^{*} \mathrm{p}<0.1$ 
Table A.10: The Median of the Estimates of 200 Miles Radius Group

\begin{tabular}{|c|c|c|c|c|}
\hline Variable & Statistics & 10 Choices & 15 Choices & 20 Choices \\
\hline \multirow{3}{*}{$\begin{array}{l}\ln (\operatorname{dist} 1) \\
\operatorname{dist} \leq 25\end{array}$} & Estimate & $-.28936^{* * *}$ & $-.29062^{* * * *}$ & $-.27805 * * * *$ \\
\hline & Std Error & $(0.0770)$ & $(0.0701)$ & $(0.0631)$ \\
\hline & Odds Ratio & 0.74874 & 0.7478 & 0.75726 \\
\hline \multirow{3}{*}{$\begin{array}{c}\ln (\text { dist } 2) \\
25<\text { dist } \leq 50\end{array}$} & Estimate & $-.45645 * * * *$ & $-.45335 * * * *$ & $-.45061 * * * *$ \\
\hline & Std Error & $(0.0553)$ & $(0.0510)$ & $(0.0499)$ \\
\hline & Odds Ratio & 0.63353 & 0.6355 & 0.63724 \\
\hline \multirow{3}{*}{$\begin{array}{c}\ln (\operatorname{dist} 3) \\
50<\operatorname{dist} \leq 75\end{array}$} & Estimate & $-.58211^{* * * *}$ & $-.58126^{* * * *}$ & $-.57619 * * * *$ \\
\hline & Std Error & $(0.0527)$ & $(0.0459)$ & $(0.0456)$ \\
\hline & Odds Ratio & 0.55872 & 0.55919 & 0.56203 \\
\hline \multirow{3}{*}{$\begin{array}{c}\ln (\operatorname{dist} 4) \\
75<\operatorname{dist} \leq 100\end{array}$} & Estimate & $-.62344^{* * * *}$ & $-.61892^{* * * *}$ & $-.61609 * * * *$ \\
\hline & Std Error & $(0.0473)$ & $(0.0451)$ & $(0.0422)$ \\
\hline & Odds Ratio & 0.5361 & 0.53853 & 0.54005 \\
\hline \multirow{3}{*}{$\begin{array}{c}\ln (\operatorname{dist} 5) \\
100<\operatorname{dist} \leq 150\end{array}$} & Estimate & $-.70941 * * * *$ & $-.70897 * * * *$ & $-.70773^{* * * *}$ \\
\hline & Std Error & $(0.0463)$ & $(0.0404)$ & $(0.0397)$ \\
\hline & Odds Ratio & 0.49193 & 0.49215 & 0.49276 \\
\hline \multirow{3}{*}{$\begin{array}{c}\ln (\operatorname{dist} 6) \\
150<\operatorname{dist} \leq 200\end{array}$} & Estimate & $-.76671 * * * *$ & $-.76478^{* * * *}$ & $-.76345^{* * * *}$ \\
\hline & Std Error & $(0.0439)$ & $(0.0414)$ & $(0.0390)$ \\
\hline & Odds Ratio & 0.46454 & 0.46543 & 0.46606 \\
\hline \multirow{3}{*}{ Cross } & Estimate & $-1.9106 * * * *$ & $-1.9237^{* * * *}$ & $-1.9362^{* * * *}$ \\
\hline & Std Error & $(0.1206)$ & $(0.1124)$ & $(0.1123)$ \\
\hline & Odds Ratio & 0.148 & 0.14606 & 0.14425 \\
\hline \multirow{3}{*}{ Size } & Estimate & $0.02055^{* * * *}$ & $0.02021^{* * * *}$ & $0.01986^{* * * *}$ \\
\hline & Std Error & $(0.0012)$ & $(0.0011)$ & $(0.0011)$ \\
\hline & Odds Ratio & 0.92076 & 0.92041 & 0.92006 \\
\hline \multirow{3}{*}{ NSLP } & Estimate & -0.12447 & -0.12682 & -0.11347 \\
\hline & Std Error & $(0.1740)$ & $(0.1752)$ & $(0.1666)$ \\
\hline & Odds Ratio & 0.88297 & 0.88089 & 0.89273 \\
\hline \multirow{3}{*}{ Minority } & Estimate & $0.35799^{*}$ & $0.35843^{*}$ & $0.33423^{*}$ \\
\hline & Std Error & $(0.1712)$ & $(0.1559)$ & $(0.1518)$ \\
\hline & Odds Ratio & 0.93045 & 0.93108 & 0.99687 \\
\hline \multirow{3}{*}{ Pupil/Teacher } & Estimate & 0.00158 & 0.00131 & 0.00143 \\
\hline & Std Error & $(0.0059)$ & $(0.0048)$ & $(0.0044)$ \\
\hline & Odds Ratio & 0.90158 & 0.90131 & 0.90143 \\
\hline
\end{tabular}

Notes: Table A.10 reports the median of the estimates with the standard error and odds ratio of a mixed logit model with different size of choices which are within 200 miles from the TPP. The standard error is a combination of the standard error of the regression and the standard error of the 101 estimates in one group. ${ }^{* * * *} \mathrm{p}<0.001,{ }^{* * *} \mathrm{p}<0.01,{ }^{* *} \mathrm{p}<0.05,{ }^{*} \mathrm{p}<0.1$ 
Table A.11: Estimation by Poisson Approach

\begin{tabular}{|c|c|c|c|c|}
\hline & Statistics & 50 Miles & 100 Miles & 200 Miles \\
\hline \multirow{3}{*}{$\begin{array}{l}\ln (\text { dist } 1) \\
\text { dist } \leq 25\end{array}$} & Estimate & $-0.4557^{* * * *}$ & $-0.441 * * * *$ & $-0.4318^{* * * *}$ \\
\hline & StdErr & $(0.041)$ & $(0.0406)$ & $(0.0405)$ \\
\hline & P-value & $<.0001$ & $<.0001$ & $<.0001$ \\
\hline \multirow{3}{*}{$\begin{array}{c}\ln (\text { dist } 2) \\
25<\text { dist } \leq 50\end{array}$} & Estimate & $-0.5782^{* * * *}$ & $-0.5631^{* * * *}$ & $-0.5501^{* * * *}$ \\
\hline & StdErr & $(0.0315)$ & $(0.031)$ & $(0.0307)$ \\
\hline & $\mathrm{P}$-value & $<.0001$ & $<.0001$ & $<.0001$ \\
\hline \multirow{3}{*}{$\begin{array}{c}\ln (\text { dist } 3) \\
50<\text { dsit } \leq 75\end{array}$} & Estimate & - & $-0.6559^{* * * *}$ & $-0.6448^{* * * *}$ \\
\hline & StdErr & - & $(0.0298)$ & $(0.0295)$ \\
\hline & P-value & - & $<.0001$ & $<.0001$ \\
\hline \multirow{3}{*}{$\begin{array}{c}\ln (\text { dist } 4) \\
75<\text { dist } \leq 100\end{array}$} & Estimate & - & $-0.6723^{* * * *}$ & $-0.6641^{* * * *}$ \\
\hline & StdErr & - & $(0.029)$ & $(0.0286)$ \\
\hline & $\mathrm{P}$-value & - & $<.0001$ & $<.0001$ \\
\hline \multirow{3}{*}{$\begin{array}{c}\ln (\operatorname{dist} 5) \\
100<\operatorname{dist} \leq 150\end{array}$} & Estimate & - & - & $-0.7378^{* * * *}$ \\
\hline & StdErr & - & - & $(0.0261)$ \\
\hline & P-value & - & - & $<.0001$ \\
\hline \multirow{3}{*}{$\begin{array}{c}\ln (\operatorname{dist} 6) \\
150<\operatorname{dist} \leq 200\end{array}$} & Estimate & - & - & $-0.7784^{* * * *}$ \\
\hline & StdErr & - & - & $(0.0287)$ \\
\hline & $\mathrm{P}$-value & - & - & $<.0001$ \\
\hline \multirow{3}{*}{ Cross } & Estimate & $-1.5699 * * * *$ & $-1.7512^{* * * *}$ & $-1.9262^{* * * *}$ \\
\hline & StdErr & $(0.1826)$ & $(0.1278)$ & $(0.1)$ \\
\hline & P-value & $<.0001$ & $<.0001$ & $<.0001$ \\
\hline \multirow{3}{*}{ Size } & Estimate & $0.0097^{* * * *}$ & $0.0098^{* * * *}$ & $0.0098^{* * * *}$ \\
\hline & StdErr & $(0.0005)$ & $(0.0004)$ & $(0.0004)$ \\
\hline & P-value & $<.0001$ & $<.0001$ & $<.0001$ \\
\hline \multirow{3}{*}{ NSLP } & Estimate & $0.05865^{*}$ & $0.04055^{*}$ & 0.02122 \\
\hline & StdErr & (0.01648) & $(0.0141)$ & $(0.01263)$ \\
\hline & P-value & 0.005 & 0.004 & 0.093 \\
\hline \multirow{3}{*}{ Minority } & Estimate & $-0.4557^{* *}$ & -0.2492 & -0.1311 \\
\hline & StdErr & $(0.153)$ & $(0.1297)$ & $(0.1159)$ \\
\hline & P-value & 0.0029 & 0.0547 & 0.2579 \\
\hline \multirow{3}{*}{ Pupil/Teacher } & Estimate & 0.0003 & 0.0005 & 0.0006 \\
\hline & StdErr & $(0.0013)$ & $(0.001)$ & $(0.001)$ \\
\hline & P-value & 0.844 & 0.6344 & 0.5487 \\
\hline
\end{tabular}

Notes: Table A.11 reports the estimates with the standard error and odds ratio of a Poisson regression with different distance from the TPP. ${ }^{* * * *} \mathrm{p}<0.001,{ }^{* * *} \mathrm{p}<0.01,{ }^{* *} \mathrm{p}<0.05,{ }^{*} \mathrm{p}<0.1$ 


\section{Appendix B}

\section{Chapter 2}

\section{B.1 Pictures and Graphs}




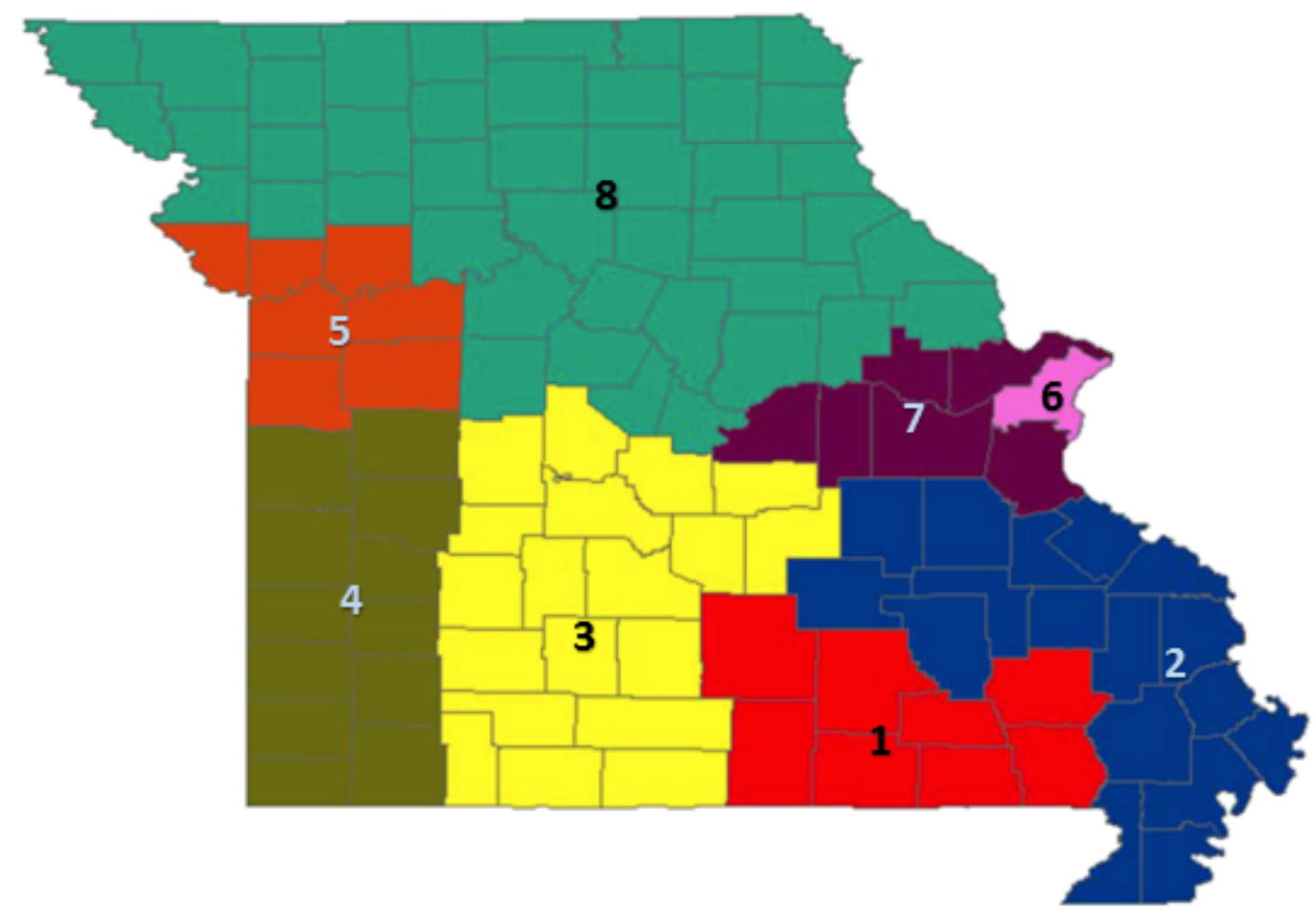

\section{Conversion Dates}

\begin{tabular}{|l|l|}
\hline June 1997 & January 1998 \\
\hline September 1997 & Feburary/March 1998 \\
\hline October 1997 & March 1998 \\
November 1997 & May 1998
\end{tabular}

Figure B.1: EBT Program Implementation Schedule Map for Missouri Counties Source: This EBT program implementation schedule map is from Wright et al. (2014) 


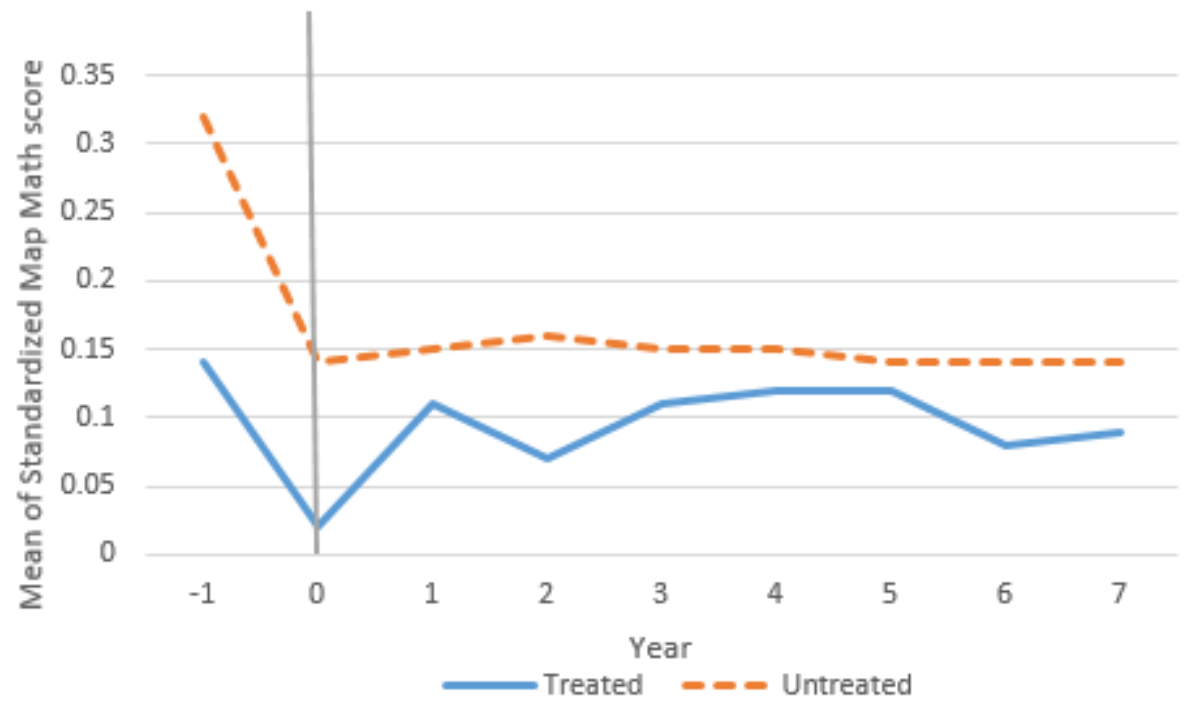

Figure B.2: Mean of the Standardized MAP Math Test Score in Grade 4 Note: Year -1 to 7 is the average standardized MAP math test score from 1997 to 2005 in grade 4

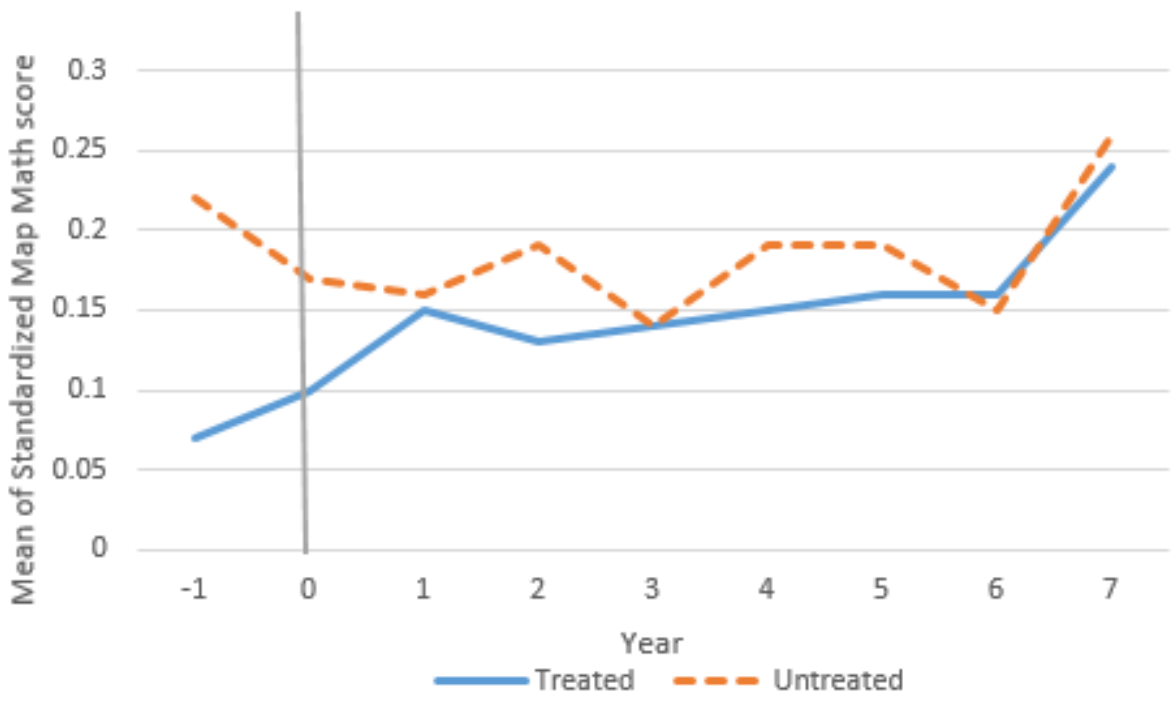

Figure B.3: Mean of the Standardized MAP Math Test Score in Grade 8 Note: Year -1 to 7 is the average standardized MAP math test score from 1997 to 2005 in grade 8 


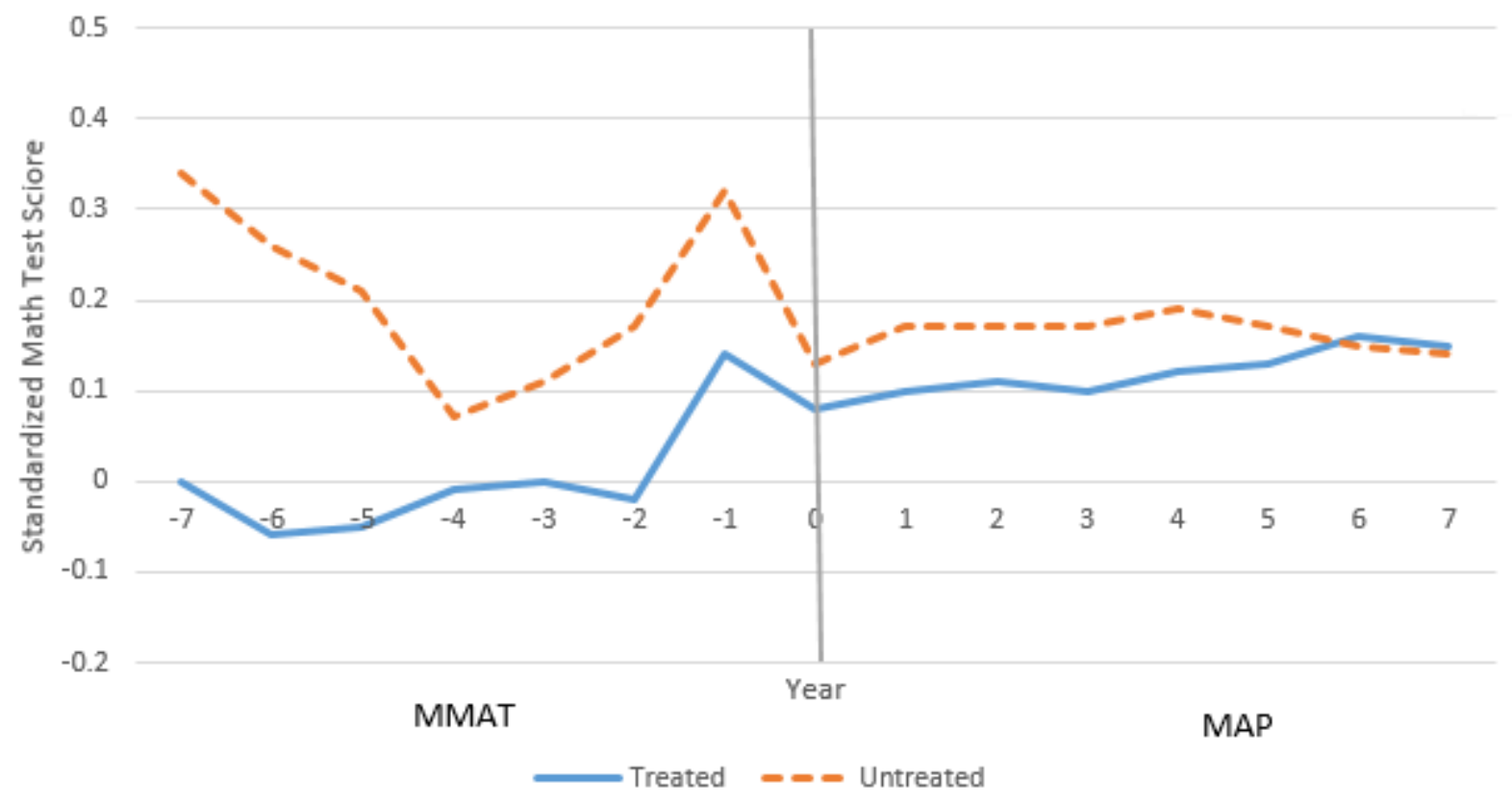

Figure B.4: Mean of the Standardized MMAT/MAP Math Test Score in Grade 4 Note: Year -7 to -2 is the average standardized MMAT math test score from 1991 to 1996, and year -1 to 7 is the average standardized MAP math test score from 1997 to 2005. All the observation conditional on the schools which took MAP math test in 1997 


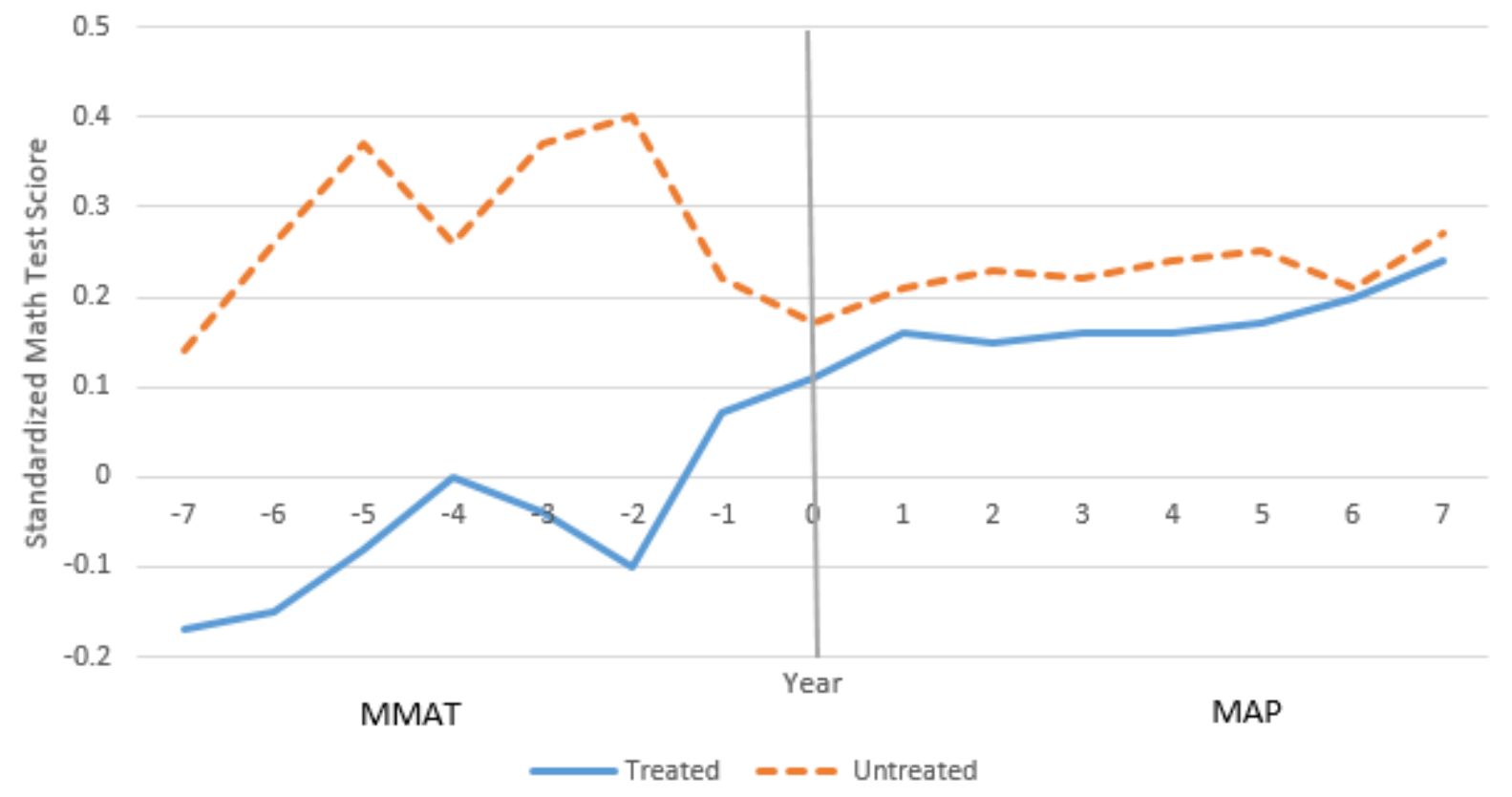

Figure B.5: Mean of the Standardized MMAT/MAP Math Test Score in Grade 8 Note: Year -7 to -2 is the average standardized MMAT math test score from 1991 to 1996, and year -1 to 7 is the average standardized MAP math test score from 1997 to 2005. All the observation conditional on the schools which took MAP math test in 1997 


\section{B.2 Tables and Charts}

Table B.1: Number of Schools Took MAP/MMAT Math Test in Grade 8

\begin{tabular}{c|llllllll}
\hline \hline Year & $\mathbf{1 9 9 5}$ & $\mathbf{1 9 9 6}$ & $\mathbf{1 9 9 7}$ & $\mathbf{1 9 9 8}$ & $\mathbf{1 9 9 9}$ & $\mathbf{2 0 0 0}$ & $\mathbf{2 0 0 1}$ & $\mathbf{2 0 0 2}$ \\
MMAT & 570 & 560 & 497 & 228 & 57 & 6 & 0 & 0 \\
MAP & 0 & 0 & 415 & 643 & 665 & 674 & 686 & 689 \\
Both MMAT and MAP & 0 & 0 & 297 & 225 & 57 & 6 & 0 & 0 \\
\hline \hline
\end{tabular}

Note: Table B.1 presents the the number of public schools took the math test in grade 8 from 1995 to 2002. The row 'MMAT' is the number of schools took MMAT math test in that year. 'MAP' represents the number of schools took MAP test. 'Both MMAT and MAP' is the number of schools took MAP and MMAT in that year.

Table B.2: Summary Statistics of Grade 4

\begin{tabular}{l|ll|ll}
\hline \hline \multirow{2}{*}{ Variable } & \multicolumn{2}{|c|}{ All sample } & \multicolumn{2}{c}{ Treated \& Untreated Group } \\
\cline { 2 - 5 } Asian-pct & Mean & StdDev & Mean & StdDev \\
\cline { 2 - 5 } Black-pct & 1.03 & 1.94 & 0.57 & 1.35 \\
Hispanic-pct & 18.57 & 29.88 & 4.73 & 9.76 \\
Indian-pct & 0.33 & 5.03 & 1.57 & 3.66 \\
White-pct & 77.99 & 30.58 & 92.73 & 11.37 \\
Female-pct & 48.32 & 4.18 & 48.43 & 4 \\
Free-lunch-pct & 48.82 & 24.62 & 51.62 & 17.58 \\
Enrollment & 352.06 & 188.42 & 292.01 & 167.97 \\
\hline \hline
\end{tabular}

Note: Table B.2 presents descriptive statistics for percent of Asian students, percent of Black students, percent of Hispanic students, percent of Indian students, percent of White students, percent of female students, percent of free lunch status, and enrollment in grade 4. 'All sample' is based on the information from all the public schools in Missouri state. 'Treated and Untreated Group' is based on the information from the public schools in our treated group or untreated group. 
Table B.3: Summary Statistics of Grade 8

\begin{tabular}{l|ll|ll}
\hline \hline \multirow{2}{*}{ Variable } & \multicolumn{2}{|c|}{ All sample } & \multicolumn{2}{c}{ Treated \& Untreated Group } \\
\cline { 2 - 5 } Asian-pct & Mean & StdDev & Mean & StdDev \\
\cline { 2 - 5 } Black-pct & 0.62 & 1.26 & 0.35 & 0.78 \\
Hispanic-pct & 12.06 & 24.83 & 3.01 & 8.02 \\
Indian-pct & 0.34 & 1.61 & 1.13 & 3.28 \\
White-pct & 85.58 & 25.7 & 0.39 & 1.72 \\
Female-pct & 47.94 & 6.83 & 48.08 & 9.1 \\
Free-lunch-pct & 43.59 & 21.38 & 45.11 & 16.51 \\
Enrollment & 366.28 & 293.84 & 278.27 & 203.97 \\
\hline \hline
\end{tabular}

Note: Table B.3 presents descriptive statistics for percent of Asian students, percent of Black students, percent of Hispanic students, percent of Indian students, percent of White students, percent of female students, percent of free lunch status, and enrollment in grade 8. 'All sample' is based on the information from all the public schools in Missouri state. 'Treated and Untreated Group' is based on the information from the public schools in our treated group or untreated group.

Table B.4: MAP standardized score of grade 4 in math

\begin{tabular}{l|lll|lll}
\hline \hline \multirow{2}{*}{ Year } & \multicolumn{3}{|c|}{ Treated } & \multicolumn{3}{c}{ Untreated } \\
& N & Mean & Median & N & Mean & Median \\
\hline 1997 & 217 & 0.14 & 0.10 & 185 & 0.32 & 0.32 \\
1998 & 360 & 0.02 & 0.06 & 240 & 0.14 & 0.19 \\
1999 & 361 & 0.11 & 0.10 & 242 & 0.15 & 0.14 \\
2000 & 360 & 0.07 & 0.07 & 242 & 0.16 & 0.17 \\
2001 & 359 & 0.11 & 0.09 & 241 & 0.15 & 0.15 \\
2002 & 359 & 0.12 & 0.11 & 241 & 0.15 & 0.11 \\
2003 & 359 & 0.12 & 0.1 & 242 & 0.14 & 0.13 \\
2004 & 361 & 0.08 & 0.13 & 243 & 0.14 & 0.14 \\
2005 & 359 & 0.09 & 0.12 & 241 & 0.14 & 0.13 \\
\hline
\end{tabular}

Note: Table B.4 reports the number of the observations, mean value, and median value of the standardized MAP math test score in grade 4 from 1997 to 2005. One group is for the treated group, and the other is the untreated group 
Table B.5: MAP standardized score of grade 8 in math

\begin{tabular}{l|lll|lll}
\hline \hline \multirow{2}{*}{ Year } & \multicolumn{3}{|c|}{ Treated } & \multicolumn{3}{c}{ Untreated } \\
& $\mathrm{N}$ & Mean & Median & N & Mean & Median \\
\hline 1997 & 145 & 0.07 & 0.03 & 116 & 0.22 & 0.25 \\
1998 & 262 & 0.1 & 0.11 & 174 & 0.17 & 0.18 \\
1999 & 263 & 0.15 & 0.14 & 180 & 0.16 & 0.21 \\
2000 & 268 & 0.13 & 0.17 & 181 & 0.19 & 0.22 \\
2001 & 269 & 0.14 & 0.14 & 182 & 0.14 & 0.2 \\
2002 & 269 & 0.15 & 0.15 & 181 & 0.19 & 0.2 \\
2003 & 271 & 0.16 & 0.17 & 181 & 0.19 & 0.22 \\
2004 & 271 & 0.16 & 0.19 & 184 & 0.15 & 0.2 \\
2005 & 270 & 0.24 & 0.24 & 181 & 0.26 & 0.26 \\
\hline
\end{tabular}

Note: Table B.5 reports the number of the observations, mean value, and median value of the standardized MAP math test score in grade 8 from 1997 to 2005 . One group is for the treated group, and the other is the untreated group 
Table B.6: MMAT and MAP standardized score of grade 4 in math

\begin{tabular}{l|lll|lll}
\hline \hline \multirow{2}{*}{ Year } & \multicolumn{3}{|c|}{ Treated } & \multicolumn{3}{c}{ Untreated } \\
& N & Mean & Median & N & Mean & Median \\
\hline 1991 & 197 & 0 & -0.05 & 182 & 0.34 & 0.29 \\
1992 & 198 & -0.06 & -0.04 & 166 & 0.26 & 0.23 \\
1993 & 197 & -0.05 & -0.1 & 184 & 0.21 & 0.18 \\
1994 & 202 & -0.01 & 0.01 & 184 & 0.07 & 0.11 \\
1995 & 204 & 0 & -0.09 & 185 & 0.11 & 0.09 \\
1996 & 211 & -0.02 & -0.03 & 184 & 0.17 & 0.13 \\
1997 & 217 & 0.14 & 0.1 & 185 & 0.32 & 0.32 \\
1998 & 212 & 0.08 & 0.09 & 182 & 0.13 & 0.19 \\
1999 & 210 & 0.1 & 0.09 & 183 & 0.17 & 0.16 \\
2000 & 205 & 0.11 & 0.09 & 183 & 0.17 & 0.17 \\
2001 & 204 & 0.1 & 0.09 & 180 & 0.17 & 0.16 \\
2002 & 200 & 0.12 & 0.09 & 179 & 0.19 & 0.12 \\
2003 & 199 & 0.13 & 0.09 & 178 & 0.17 & 0.13 \\
2004 & 198 & 0.16 & 0.14 & 179 & 0.15 & 0.15 \\
2005 & 198 & 0.15 & 0.13 & 175 & 0.14 & 0.13 \\
\hline
\end{tabular}

Note: Table B.6 reports the number of the observations, mean value, and median value of the treated group and the untreated group in grade 4. From 1991 to 1996 based on standardized MMAT math test score and from 1997 to 2005 based on standardized MAP math test score. The sample is the conditional sample which means all the observations in this table need to take the MAP test in 1997. 
Table B.7: MMAT and MAP standardized score of grade 8 in math

\begin{tabular}{l|lll|lll}
\hline \hline \multirow{2}{*}{ Year } & \multicolumn{3}{|c|}{ Treated } & \multicolumn{3}{c}{ Untreated } \\
& $\mathrm{N}$ & Mean & Median & $\mathrm{N}$ & Mean & Median \\
\hline 1991 & 106 & -0.17 & -0.2 & 97 & 0.14 & 0.11 \\
1992 & 110 & -0.15 & -0.24 & 99 & 0.26 & 0.22 \\
1993 & 115 & -0.08 & -0.15 & 98 & 0.37 & 0.25 \\
1994 & 119 & 0 & -0.04 & 100 & 0.26 & 0.28 \\
1995 & 131 & -0.04 & -0.13 & 104 & 0.37 & 0.26 \\
1996 & 138 & -0.1 & -0.12 & 105 & 0.4 & 0.44 \\
1997 & 145 & 0.07 & 0.03 & 116 & 0.22 & 0.25 \\
1998 & 141 & 0.11 & 0.13 & 112 & 0.17 & 0.19 \\
1999 & 137 & 0.16 & 0.16 & 112 & 0.21 & 0.22 \\
2000 & 133 & 0.15 & 0.18 & 111 & 0.23 & 0.25 \\
2001 & 127 & 0.16 & 0.15 & 111 & 0.22 & 0.21 \\
2002 & 124 & 0.16 & 0.14 & 111 & 0.24 & 0.23 \\
2003 & 122 & 0.17 & 0.16 & 111 & 0.25 & 0.26 \\
2004 & 120 & 0.2 & 0.2 & 111 & 0.21 & 0.22 \\
2005 & 121 & 0.24 & 0.24 & 109 & 0.27 & 0.26 \\
\hline
\end{tabular}

Note: Table B.7 reports the number of the observations, mean value, and median value of the treated group and the untreated group in grade 8. From 1991 to 1996 based on standardized MMAT math test score and from 1997 to 2005 based on standardized MAP math test score. The sample is the conditional sample which means all the observations in this table need to take the MAP test in 1997. 
Table B.8: MMAT and MAP standardized score of grade 4 in math conditional

\begin{tabular}{c|cll|cll}
\hline \hline \multirow{2}{*}{ Year } & \multicolumn{3}{|c|}{ Treated } & \multicolumn{3}{c}{ Untreated } \\
& $\mathrm{N}$ & Mean & Median & $\mathrm{N}$ & Mean & Median \\
\hline 1997 & 198 & 0.17 & 0.11 & 173 & 0.34 & 0.34 \\
1998 & 198 & 0.09 & 0.09 & 173 & 0.13 & 0.19 \\
1999 & 198 & 0.10 & 0.09 & 173 & 0.18 & 0.17 \\
2000 & 198 & 0.11 & 0.08 & 173 & 0.18 & 0.18 \\
2001 & 198 & 0.11 & 0.10 & 173 & 0.18 & 0.16 \\
2002 & 198 & 0.12 & 0.10 & 173 & 0.19 & 0.12 \\
2003 & 198 & 0.13 & 0.09 & 173 & 0.17 & 0.13 \\
2004 & 198 & 0.16 & 0.14 & 173 & 0.15 & 0.15 \\
2005 & 198 & 0.15 & 0.13 & 173 & 0.13 & 0.13 \\
\hline
\end{tabular}

Note: Table B.8 reports the number of the observations, mean value, and median value of the treated group and the untreated group in grade 8 . The sample is the conditional sample which means all the observations in this table need to take all the MAP tests from 1997 to 2005.

Table B.9: MMAT and MAP standardized score of grade 8 in math conditional

\begin{tabular}{c|cll|cll}
\hline \hline \multirow{2}{*}{ Year } & \multicolumn{3}{|c|}{ Treated } & \multicolumn{3}{c}{ Untreated } \\
& $\mathrm{N}$ & Mean & Median & $\mathrm{N}$ & Mean & Median \\
\hline 1997 & 120 & 0.09 & 0.07 & 107 & 0.23 & 0.25 \\
1998 & 120 & 0.12 & 0.15 & 107 & 0.17 & 0.18 \\
1999 & 120 & 0.17 & 0.17 & 107 & 0.21 & 0.22 \\
2000 & 120 & 0.17 & 0.18 & 107 & 0.24 & 0.25 \\
2001 & 120 & 0.17 & 0.15 & 107 & 0.23 & 0.21 \\
2002 & 120 & 0.17 & 0.14 & 107 & 0.24 & 0.23 \\
2003 & 120 & 0.17 & 0.16 & 107 & 0.25 & 0.26 \\
2004 & 120 & 0.20 & 0.20 & 107 & 0.22 & 0.22 \\
2005 & 120 & 0.24 & 0.25 & 107 & 0.27 & 0.26 \\
\hline
\end{tabular}

Note: Table B.9 reports the number of the observations, mean value, and median value of the treated group and the untreated group in grade 8 . The sample is the conditional sample which means all the observations in this table need to take all the MAP tests from 1997 to 2005 . 
Table B.10: Difference-in-Difference of the Standardized MAP Math Test Score of Unconditional Group in Grade 4

\begin{tabular}{|c|c|c|}
\hline & \multicolumn{2}{|c|}{ Treatment } \\
\hline & $\begin{array}{l}\text { Untreated } \\
\text { Mean }\end{array}$ & $\begin{array}{c}\text { Treated } \\
\text { Mean }\end{array}$ \\
\hline \multirow{2}{*}{ Event } & 0.14 & 0.14 \\
\hline & 0.15 & 0.11 \\
\hline Diff & -0.18 & -0.03 \\
\hline Diff-in-Diff & \multicolumn{2}{|c|}{0.15} \\
\hline
\end{tabular}

Note: Table B.10 presents the calculate results of the Difference-in-Difference method based on standardized MAP math test score of unconditional sample in grade 4. 'Before' represents year 1997, and 'After' represents 1998 to 2005. 'Diff' is using the number 'After' minus 'Before'. 'Diffin-Diff' is using the 'Diff' in treated group minus the 'Diff' in untreated group. The unit of the results is standard deviation.

Table B.11: Difference-in-Difference of the MAP Math Test Standardized Score of Unconditional Group in Grade 8

\begin{tabular}{cc|lc}
\hline \hline & \multicolumn{2}{|c}{ Treatment } \\
& & $\begin{array}{c}\text { Untreated } \\
\text { Mean }\end{array}$ & $\begin{array}{c}\text { Treated } \\
\text { Mean }\end{array}$ \\
\hline \multirow{2}{*}{ Event } & Before & 0.22 & 0.07 \\
After & 0.17 & 0.16 \\
\hline Diff & -0.05 & 0.09 \\
\hline \multicolumn{2}{|c}{ Diff-in-Diff } & \multicolumn{2}{|c}{0.14} \\
\hline
\end{tabular}

Note: Table B.11 presents the calculate results of the Difference-in-Difference method based on standardized MAP math test score of unconditional sample in grade 8. 'Before' represents year 1997, and 'After' represents 1998 to 2005. 'Diff' is using the number 'After' minus 'Before'. 'Diffin-Diff' is using the 'Diff' in treated group minus the 'Diff' in untreated group. The unit of the results is standard deviation. 
Table B.12: Difference-in-Difference Estimates of the Unconditional Sample with School Fixed Effect

\begin{tabular}{cll}
\hline \hline & \multicolumn{2}{c}{ Grade } \\
\hline Variable & \multicolumn{1}{c}{$\mathbf{4}$} & \multicolumn{1}{c}{$\mathbf{8}$} \\
\hline Event & $-0.119^{*}$ & 0.003 \\
& $(0.064)$ & $(0.026)$ \\
treat*event & 0.024 & $0.053^{* * *}$ \\
& $(0.061)$ & $(0.015)$ \\
Pct of White & $0.003^{* *}$ & 0.001 \\
& $(0.001)$ & $(0.002)$ \\
$\log ($ enroll $)$ & -0.018 & 0.025 \\
& $(0.024)$ & $(0.019)$ \\
Constant & -0.003 & -0.123 \\
& $(0.235)$ & $(0.206)$ \\
Observations & 5,211 & 3,842 \\
R-squared & 0.006 & 0.005 \\
Number of schools & 648 & 506 \\
\hline \hline
\end{tabular}

Note: Table B.12 reports the difference-indifferent model estimates of the unconditional sample in grade 4 and grade 8 . Standard errors are clustered at the school level. *** $\mathrm{p}<0.01,{ }^{*} * \mathrm{p}<0.05,{ }^{*} \mathrm{p}<0.1$ 
Table B.13: Difference-in-Difference of the Standardized MAP Math Test Score of Conditional Grade 4

\begin{tabular}{|c|c|c|}
\hline & \multicolumn{2}{|c|}{ Treatment } \\
\hline & $\begin{array}{l}\text { Untreated } \\
\text { Mean }\end{array}$ & $\begin{array}{c}\text { Treated } \\
\text { Mean }\end{array}$ \\
\hline \multirow{2}{*}{ Event } & 0.34 & 0.17 \\
\hline & 0.13 & 0.14 \\
\hline Diff & -0.21 & -0.03 \\
\hline Diff-in-Diff & \multicolumn{2}{|c|}{0.18} \\
\hline
\end{tabular}

Note: Table B.13 presents the calculate results of the Difference-in-Difference method based on standardized MAP math test score of unconditional sample in grade 4. 'Before' represents year 1997, and 'After' represents 1998 to 2005. 'Diff' is using the number 'After' minus 'Before'. 'Diffin-Diff' is using the 'Diff' in treated group minus the 'Diff' in untreated group. The unit of the results is standard deviation.

Table B.14: Difference-in-Difference of the Standardized MAP Math Test Score of Conditional Grade 8

\begin{tabular}{cc|lc}
\hline \hline & \multicolumn{2}{|c}{ Treatment } \\
& & $\begin{array}{c}\text { Untreated } \\
\text { Mean }\end{array}$ & $\begin{array}{c}\text { Treated } \\
\text { Mean }\end{array}$ \\
\hline \multirow{2}{*}{ Event } & Before & 0.23 & 0.09 \\
After & 0.17 & 0.20 \\
\hline Diff & -0.05 & 0.11 \\
\hline \multicolumn{2}{|c}{ Diff-in-Diff } & \multicolumn{2}{|c}{0.16} \\
\hline
\end{tabular}

Note: Table B.14 presents the calculate results of the Difference-in-Difference method based on standardized MAP math test score of conditional sample in grade 8. 'Before' represents year 1997, and 'After' represents 1998 to 2005. 'Diff' is using the number 'After' minus 'Before'. 'Diffin-Diff' is using the 'Diff' in treated group minus the 'Diff' in untreated group. The unit of the results is standard deviation. 
Table B.15: Difference-in-Difference Estimates of the Conditional Sample with School Fixed Effect

\begin{tabular}{cll}
\hline \hline & \multicolumn{2}{c}{ Grade } \\
\hline Variable & \multicolumn{1}{c}{$\mathbf{4}$} & \multicolumn{1}{c}{$\mathbf{8}$} \\
\hline Event & $-0.154^{*}$ & -0.020 \\
& $(0.080)$ & $(0.028)$ \\
treat*event & 0.055 & $0.070^{* * *}$ \\
& $(0.079)$ & $(0.019)$ \\
Pct of White & $0.004^{* * *}$ & $0.004^{*}$ \\
& $(0.001)$ & $(0.002)$ \\
log(enroll) & -0.057 & 0.001 \\
& $(0.036)$ & $(0.037)$ \\
Constant & 0.189 & -0.197 \\
& $(0.277)$ & $(0.339)$ \\
Observations & 3,339 & 2,043 \\
R-squared & 0.015 & 0.015 \\
Number of schools & 371 & 227 \\
\hline \hline
\end{tabular}

Note: Table B.15 reports the difference-indifferent model estimates of the conditional sample in grade 4 and grade 8 . Standard errors are clustered at the school level. ${ }^{* * *} \mathrm{p}<0.01$, ** $\mathrm{p}<0.05,{ }^{*} \mathrm{p}<0.1$ 
Table B.16: Difference-in-Difference Estimates of the Unconditional Sample with School Fixed Effect and Cluster at County Level

\begin{tabular}{cll}
\hline \hline & \multicolumn{2}{c}{ Grade } \\
\hline Variable & \multicolumn{1}{c}{$\mathbf{4}$} & \multicolumn{1}{c}{$\mathbf{8}$} \\
\hline Event & $-0.119^{*}$ & 0.003 \\
& $(0.068)$ & $(0.029)$ \\
treat*event & 0.024 & $0.053^{* * *}$ \\
& $(0.069)$ & -0.017 \\
Pct of White & $0.003^{* *}$ & 0.001 \\
& -0.002 & $(0.002)$ \\
$\log ($ enroll $)$ & -0.018 & 0.025 \\
& -0.031 & -0.025 \\
Constant & -0.003 & -0.123 \\
& -0.286 & -0.242 \\
Observations & 5,211 & 3,842 \\
R-squared & 0.009 & 0.025 \\
Number of schools & 648 & 506 \\
\hline \hline
\end{tabular}

Note: Table B.16 reports the difference-indifferent model estimates of the conditional sample in grade 4 and grade 8 . Standard errors are clustered at the county level. *** $\mathrm{p}<0.01,{ }^{* *} \mathrm{p}<0.05,{ }^{*} \mathrm{p}<0.1$ 
Table B.17: Difference-in-Difference Estimates of the Conditional Sample with School Fixed Effect and Cluster at County Level

\begin{tabular}{cll}
\hline \hline & \multicolumn{2}{c}{ Grade } \\
\hline Variable & \multicolumn{1}{c}{$\mathbf{4}$} & \multicolumn{1}{c}{$\mathbf{8}$} \\
\hline Event & $-0.154^{*}$ & -0.020 \\
& $(0.086)$ & $(0.032)$ \\
treat*event & 0.055 & $0.070^{* * *}$ \\
& $(0.062)$ & $(0.018)$ \\
Pct of White & $0.004^{* * *}$ & $0.004^{*}$ \\
& $(0.002)$ & $(0.002)$ \\
$\log ($ enroll $)$ & -0.057 & 0.001 \\
& $(0.038)$ & $(0.04)$ \\
Constant & 0.189 & -0.197 \\
& $(0.312)$ & -0.368 \\
Observations & 3,467 & 2,173 \\
R-squared & 0.013 & 0.035 \\
Number of schools & 402 & 260 \\
\hline \hline
\end{tabular}

Note: Table B.17 reports the difference-indifferent model estimates of the conditional sample in grade 4 and grade 8 . Standard errors are clustered at the county level. ${ }^{* * *} \mathrm{p}<0.01$, ** $\mathrm{p}<0.05,{ }^{*} \mathrm{p}<0.1$ 
Table B.18: Difference-in-Difference Estimates of Unconditional Sample in 1997 and 1998 with School Fixed Effect

\begin{tabular}{cll}
\hline & \multicolumn{2}{c}{ Grade } \\
\hline Variable & \multicolumn{1}{c}{$\mathbf{4}$} & \multicolumn{1}{c}{$\mathbf{8}$} \\
\hline Event & $-0.195^{* *}$ & -0.057 \\
& $(0.082)$ & $(0.034)$ \\
treat*event & 0.124 & $0.090^{* *}$ \\
& $(0.092)$ & $(0.045)$ \\
Pct of White & -0.003 & 0.002 \\
& $(0.012)$ & $(0.016)$ \\
$\log ($ enroll $)$ & 0.392 & 0.026 \\
& $(0.648)$ & $(0.257)$ \\
Constant & -1.714 & -0.178 \\
& $(3.668)$ & $(2.093)$ \\
& & \\
Observations & 1,002 & 695 \\
R-squared & 0.028 & 0.017 \\
Number of schools & 608 & 442 \\
\hline \hline
\end{tabular}

Note: Table B.18 reports the difference-indifferent model estimates of the unconditional sample from 1997 to 1998 in grade 4 and grade 8 . Standard errors are clustered at the school level. ${ }^{* * *} \mathrm{p}<0.01,{ }^{* *} \mathrm{p}<0.05$, $* \mathrm{p}<0.1$ 
Table B.19: Difference-in-Difference Estimates of Conditional Sample in 1997 and 1998 with School Fixed Effect

\begin{tabular}{cll}
\hline \hline & \multicolumn{2}{c}{ Grade } \\
\hline Variable & \multicolumn{1}{c}{$\mathbf{4}$} & \multicolumn{1}{c}{$\mathbf{8}$} \\
\hline Event & $-0.195^{* *}$ & -0.057 \\
& $(0.082)$ & $(0.034)$ \\
treat*event & 0.124 & $0.090^{* *}$ \\
& $(0.092)$ & $(0.045)$ \\
Pct of White & -0.003 & 0.002 \\
& $(0.012)$ & $(0.016)$ \\
$\log ($ enroll $)$ & 0.392 & 0.026 \\
& $(0.649)$ & $(0.258)$ \\
Constant & -1.700 & -0.172 \\
& $(3.685)$ & $(2.102)$ \\
& & \\
Observations & 796 & 513 \\
R-squared & 0.028 & 0.017 \\
Number of schools & 402 & 260 \\
\hline \hline
\end{tabular}

Note: Table B.18 reports the difference-indifferent model estimates of the conditional sample from 1997 to 1998 in grade 4 and grade 8 . Standard errors are clustered at the school level. ${ }^{* * *} \mathrm{p}<0.01,{ }^{* *} \mathrm{p}<0.05,{ }^{*} \mathrm{p}<0.1$ 


\section{Bibliography}

Elaine Allensworth, Stephen Ponisciak, and Christopher Mazzeo. The schools teachers leave: Teacher mobility in chicago public schools. Consortium on Chicago School Research, 2009.

Laura E Armey, Jonathan Lipow, and Natalie J Webb. The impact of electronic financial payments on crime. Information Economics and Policy, 29:46-57, 2014.

Louis-Philippe Beland and Dongwoo Kim. The effect of high school shootings on schools and student performance. Educational Evaluation and Policy Analysis, page $0162373715590683,2015$.

Steven L Berman, William M Kurtines, Wendy K Silverman, and Lourdes T Serafini. The impact of exposure to crime and violence on urban youth. American journal of orthopsychiatry, 66(3):329, 1996.

Donald Boyd, Hamilton Lankford, Susanna Loeb, and James Wyckoff. The draw of home: How teachers' preferences for proximity disadvantage urban schools. Journal of Policy Analysis and Management, 24(1):113-132, 2005.

J Hayden Boyd and Robert E Mellman. The effect of fuel economy standards on the us automotive market: an hedonic demand analysis. Transportation Research Part A: General, 14(5-6):367-378, 1980. 
N Scott Cardell and Frederick C Dunbar. Measuring the societal impacts of automobile downsizing. Transportation Research Part A: General, 14(5-6):423-434, 1980.

Greg Chen and Lynne A Weikart. Student background, school climate, school disorder, and student achievement: An empirical study of new york city's middle schools. Journal of School Violence, 7(4):3-20, 2008.

Jane G Coggshall and Susan K Sexton. Teachers on the move: A look at teacher interstate mobility policy and practice. National Association of State Directors of Teacher Education and Certification (NJ1), 2008.

Dewey G Cornell and Matthew J Mayer. Why do school order and safety matter? Educational Researcher, 39(1):7-15, 2010.

Robert M Costrell and Michael Podgursky. Distribution of benefits in teacher retirement systems and their implications for mobility. Education, 5(4):519-557, 2010.

Christiadi Cushing and Brian Cushing. Conditional logit, iia, and alternatives for estimating models of interstate migration. In annual meeting of the Southern Regional Science Association. Charleston, SC, 2007.

Ana M Elfers, Margaret L Plecki, and Michael S Knapp. Teacher mobility: Looking more closely at" the movers" within a state system. Peabody Journal of Education, 81(3):94-127, 2006.

C Fritz Foley. Welfare payments and crime. The review of Economics and Statistics, 93(1):97-112, 2011.

Dan Goldhaber, Cyrus Grout, Kristian L Holden, and Nate Brown. Barriers to cross- 
state mobility in the teaching profession: Evidence from oregon and washington. Educational Research, 44(8):421-431, 2015a.

Dan Goldhaber, Cyrus Grout, Kristian L Holden, and Nate Brown. Crossing the border? exploring the cross-state mobility of the teacher workforce. Educational Researcher, page 0013189X15613981, 2015b.

Lucinda Gray, Rebecca Goldring, and Soheyla (NCES 2015-388) Taie. User's manual for the first through fifth waves of the 2007-08 restricted-use beginning teacher longitudinal study data file. U.S. Department of Education. Washington,DC: National Center for Education Statistics, 2015.

Jeffrey Grogger. Local violence and educational attainment. Journal of human resources, pages 659-682, 1997.

Paulo Guimaraes, Octávio Figueirdo, and Douglas Woodward. A tractable approach to the firm location decision problem. Review of Economics and Statistics, 85(1): 201-204, 2003.

Paulo Guimaraes, Octávio Figueiredo, and Douglas Woodward. Industrial location modeling: extending the random utility framework. Journal of Regional Science, 44(1):1-20, 2004.

Eric A Hanushek, John F Kain, and Steven G Rivkin. Why public schools lose teachers. Journal of human resources, 39(2):326-354, 2004.

Laveria F Hutchison. Addressing the stem teacher shortage in american schools: Ways to recruit and retain effective stem teachers. Action in Teacher Education, 34(5-6): 541-550, 2012. 
Dongwoo Kim. The effect of violent crime on educational attainment: Evidence from the implementation of the electronic benefit transfer program. Working Paper, 2016.

Dongwoo Kim, Cory Koedel, Shawn Ni, Michael Podgursky, et al. Labor market frictions and production efficiency in public schools. Technical report, 2016.

Cory Koedel, Jason A Grissom, Shawn X Ni, and Michael J Podgursky. Pensioninduced rigidities in the labor market for school leaders. 2011.

Gayla Margolin and Elana B Gordis. The effects of family and community violence on children. Annual review of psychology, 51(1):445-479, 2000.

Daniel McFadden. Modeling the choice of residential location. Transportation Research Record, (673), 1978.

Daniel McFadden et al. Conditional logit analysis of qualitative choice behavior. 1973.

Mary E Schwab-Stone, Tim S Ayers, Wesley Kasprow, Charlene Voyce, Charles Barone, Timothy Shriver, and Roger P Weissberg. No safe haven: A study of violence exposure in an urban community. Journal of the American Academy of Child $\mathscr{E}$ Adolescent Psychiatry, 34(10):1343-1352, 1995.

Train. Discrete choice methods with simulation, 2003.

Richard Wright and Volkan Topalli. Choosing street crime. Oxford handbook of criminological theory, page 461, 2013.

Richard Wright, Erdal Tekin, Volkan Topalli, Chandler McClellan, Timothy Dickinson, and Richard Rosenfeld. Less cash, less crime: Evidence from the electronic benefit transfer program. Technical report, National Bureau of Economic Research, 2014. 
Richard T Wright and Scott H Decker. Burglars on the job: Streetlife and residential break-ins. UPNE, 1996. 


\section{VITA}

I was born in a working-class family in Tianjin, China as the only child of the family. My parents never went to a college, but they really pay attention to my

education. I went to top-tier high school and top-tier College all the way. I got my Bachelor degree from Nankai University in 2009. I was hired by Tianjin House Fund Management Center as a risk analyst for three years before I came to the U.S. for Ph.D. study. My major was Finance when I was an undergraduate, but when I start my research at the Economics department of the University of Missouri I find education in economics is really an interesting topic. I decided to dedicate my time and effort in this field.

Another reason I choose education of economics as my dissertation topic is that I plan to be an awesome dad in the future. Like my parents, I pay attention to kid's education as well. The study in this field can help me get a better understanding. As same-sex couple things are really hard for us to achieve, sometimes. My husband, Tengfei, and I got married in 2013. At that time same-sex marriage was still illegal in the Federal government. Five years later, we will be parents with the help of surrogacy. Our experiences in the past five years make me believe that life sometimes is tough, but it worth us to fight to make it better. 